4

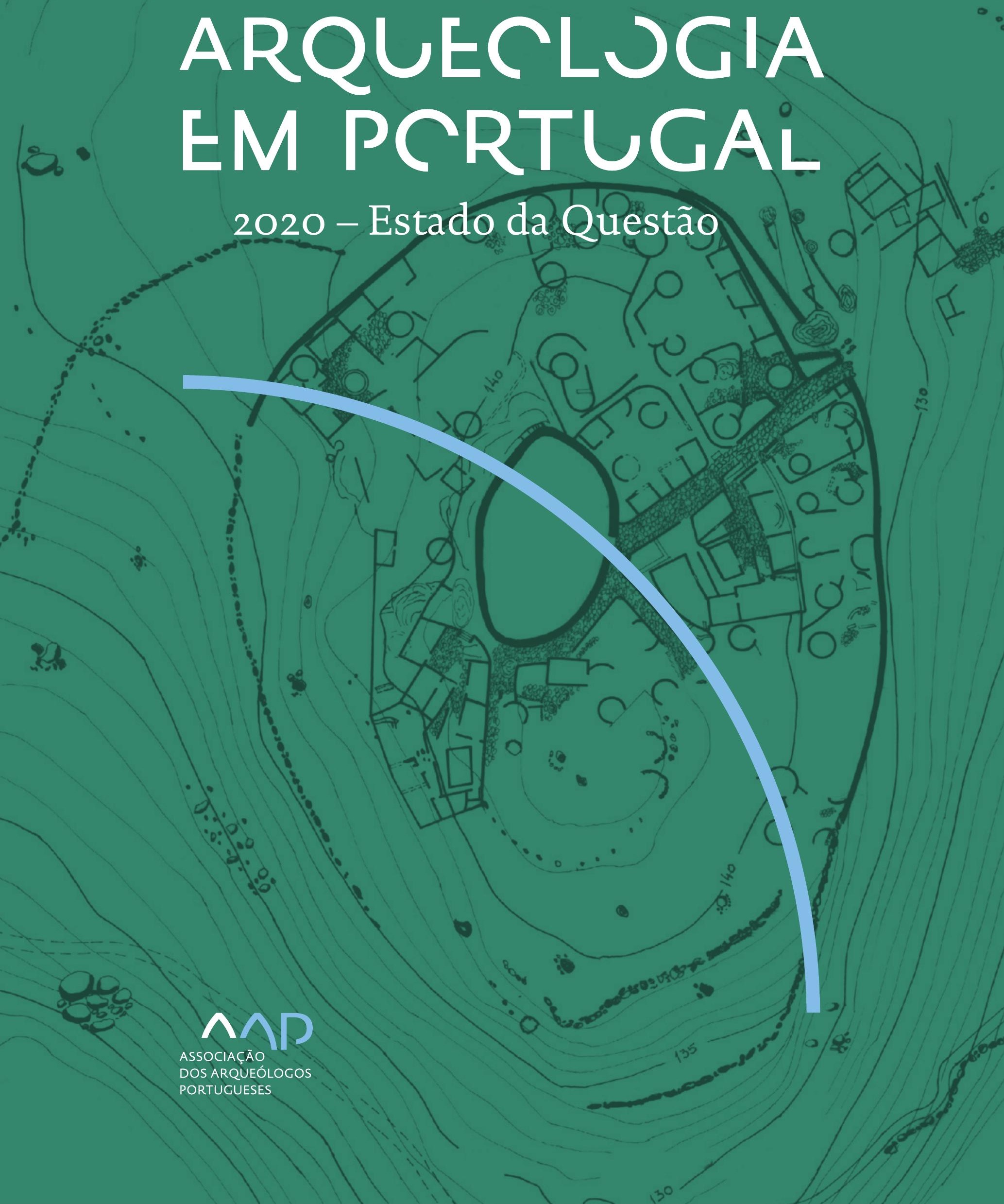


Coordenação editorial: José Morais Arnaud, César Neves e Andrea Martins Design gráfico: Flatland Design

AAP - ISBN: 978-972-9451-89-8

CITCEM - ISBN: 978-989-8970-25-1

Associação dos Arqueólogos Portugueses e CITCEM

Lisboa, 2020

O conteúdo dos artigos é da inteira responsabilidade dos autores. Sendo assim a Associação dos Arqueólogos Portugueses declina qualquer responsabilidade por eventuais equívocos ou questões de ordem ética e legal.

Desenho de capa:

Planta do castro de Monte Mozinho (Museu Municipal de Penafiel).

\section{$\hat{\wedge} \mathrm{P}$}

DOS ARQUEÓLOGOS PORTUGUESES

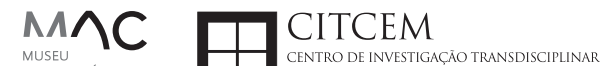
MUSEU
ARQUELLÓGICO
DO CARMO
U.PORTO

FLUP FACULDADE DE LETRAS
UNIVERSIDADE DO PORTO

Apoio

EC para a Ciência 


\section{Índice}

15 Prefácio

José Morais Arnaud

\section{Historiografia e Teoria}

17 Território, comunidade, memória e emoção: a contribuição da história da arqueologia (algumas primeiras e breves reflexões)

Ana Cristina Martins

25 Como descolonizar a arqueologia portuguesa?

Rui Gomes Coelho

41 Arqueologia e Modernidade: uma revisitação pessoal e breve de alguns aspetos da obra homónima de Julian Thomas de 2004

Vítor Oliveira Jorge

57 Dados para a História das Mulheres na Arqueologia portuguesa, dos finais do século XIX aos inícios do século XX: números, nomes e tabelas

Filipa Dimas / Mariana Diniz

73 Retractos da arqueologia portuguesa na imprensa: (in)visibilidades no feminino

Catarina Costeira / Elsa Luís

85 Arqueologia e Arqueólogos no Norte de Portugal Jacinta Bugalhão

101 Vieira Guimarães (1864-1939) e a arqueologia em Tomar: uma abordagem sobre o território e as gentes

João Amendoeira Peixoto / Ana Cristina Martins

115 Os memoráveis? A arqueologia algarvia na imprensa nacional e regional na presente centúria (2001-2019): características, visões do(s) passado(s) e a arqueologia

enquanto marca

Frederico Agosto / João Silva

129 A Evolução da Arqueologia Urbana e a Valorização Patrimonial no Barlavento Algarvio: Os casos de Portimão e Silves

Artur Mateus / Diogo Varandas / Rafael Boavida

\section{Gestão, Valorização e Salvaguarda do Património}

145 O Caderno Reivindicativo e as condições de trabalho em Arqueologia Miguel Rocha / Liliana Matias Carvalho / Regis Barbosa / Mauro Correia / Sara Simões / Jacinta Bugalhão / Sara Brito / Liliana Veríssimo Carvalho / Richard Peace / Pedro Peça / Cézer Santos

155 Os Estudos de Impacte Patrimonial como elemento para uma estratégia sustentável de minimização de impactes no âmbito de reconversões agrícolas Tiago do Pereiro

165 Salvaguarda de Património arqueológico em operações florestais: gestão e sensibilização Filipa Bragança / Gertrudes Zambujo / Sandra Lourenço / Belém Paiva / Carlos Banha / Frederico Tatá Regala / Helena Moura / Jacinta Bugalhão / João Marques / José Correia / Pedro Faria / Samuel Melro

179 Os valores do Património: uma investigação sobre os Sítios Pré-históricos de Arte Rupestre do Vale do Rio Côa e de Siega Verde José Paulo Francisco 
189 Conjugando recursos arqueológicos e naturais para potenciar as visitas ao Geoparque Litoral de Viana do Castelo (Noroeste de Portugal)

Hugo A. Sampaio / Ana M.S. Bettencourt / Susana Marinho / Ricardo Carvalhido

203 Áreas de Potencial Arqueológico na Região do Médio Tejo: Modelo Espacial Preditivo Rita Ferreira Anastácio / Ana Filipa Martins / Luiz Oosterbeek

223 Património Arqueológico e Gestão Territorial: O contributo da Arqueologia para a revisão do PDM de Avis

Ana Cristina Ribeiro

237 A coleção arqueológica do extinto Museu Municipal do Porto - Origens, Percursos e Estudos

Sónia Couto

251 Valpaços - uma nova carta arqueológica

Pedro Pereira / Maria de Fátima Casares Machado

263 Arqueologia na Cidade de Peniche

Adriano Constantino / Luís Rendeiro

273 Arqueologia Urbana: a cidade de Lagos como caso de Estudo Cátia Neto

285 Estratégias de promoção do património cultural subaquático nos Açores. O caso da ilha do Faial

José Luís Neto / José Bettencourt / Luís Borges / Pedro Parreira

297 Carta Arqueológica da Cidade Velha: Uma primeira abordagem

Jaylson Monteiro / Nireide Tavares / Sara da Veiga / Claudino Ramos / Edson Brito /

Carlos Carvalho / Francisco Moreira / Adalberto Tavares

311 Antropologia Virtual: novas metodologias para a análise morfológica e funcional Ricardo Miguel Godinho / Célia Gonçalves

\section{Didáctica da Arqueologia}

327 Como os projetos de Arqueologia podem contribuir para uma comunidade culturalmente mais consciente Alexandra Figueiredo / Claúdio Monteiro / Adolfo Silveira / Ricardo Lopes

337 Educação Patrimonial - Um cidadão esclarecido é um cidadão ativo! Ana Paula Almeida

351 A aproximação da Arqueologia à sala de aula: um caso de estudo no $3^{\circ}$ ciclo do Ensino Básico Luís Serrão Gil

363 Arqueologia 3.o - Pensar e comunicar a Arqueologia para um futuro sustentável Mónica Rolo

377 “Conversa de Arqueólogos" - Divulgar a Arqueologia em tempos de Pandemia Diogo Teixeira Dias

389 Escola Profissional de Arqueologia: desafios e oportunidades Susana Nunes / Dulcineia Pinto / Júlia Silva / Ana Mascarenhas

399 Os Museus de Arqueologia e os Jovens: a oferta educativa para o público adolescente Beatriz Correia Barata / Leonor Medeiros

411 O museu universitário como mediador entre a ciência e a sociedade: o exemplo da secção de arqueologia no Museu de História Natural e da Ciência da Universidade do Porto (MHNC-UP)

Rita Gaspar 
421 Museu de Lanifícios: Real Fábrica de Panos. Atividades no âmbito da Arqueologia Beatriz Correia Barata / Rita Salvado

427 Arqueologia Pública e o caso da localidade da Mata (Torres Novas) Cláudia Manso / Ana Rita Ferreira / Cristiana Ferreira / Vanessa Cardoso Antunes

431 Do sítio arqueológico ao museu: um percurso (também) didático Lídia Fernandes

447 Estão todos convidados para a Festa! E para dançar também... O projecto do Serviço Educativo do Museu Arqueológico do Carmo na $5^{\underline{a}}$ Edição da Festa da Arqueologia Rita Pires dos Santos

459 O “Clã de Carenque”, um projeto didático de arqueologia Eduardo Gonzalez Rocha

469 Mediação cultural: peixe que puxa carroça nas Ruínas Romanas de Troia Inês Vaz Pinto / Ana Patrícia Magalhães / Patrícia Brum / Filipa Santos

481 Didática Arqueológica, experiências do Projeto Mértola Vila Museu Maria de Fátima Palma / Clara Rodrigues / Susana Gómez / Lígia Rafael

\section{Arte Rupestre}

497 Os inventários de arte rupestre em Portugal Mila Simões de Abreu

513 O projeto FIRST-ART - conservação, documentação e gestão das primeiras manifestações de arte rupestre no Sudoeste da Península Ibérica: as grutas do Escoural e Maltravieso Sara Garcês / Hipólito Collado / José Julio García Arranz / Luiz Oosterbeek / António Carlos Silva / Pierluigi Rosina / Hugo Gomes / Anabela Borralheiro Pereira / George Nash / Esmeralda Gomes / Nelson Almeida / Carlos Carpetudo

523 Trabalhos de documentação de arte paleolítica realizados no âmbito do projeto PalæoCôa André Tomás Santos / António Fernando Barbosa / Luís Luís / Marcelo Silvestre / Thierry Aubry

537 Imagens fantasmagóricas, silhuetas elusivas: as figuras humanas na arte do Paleolítico Superior da região do Côa Mário Reis

$55^{1}$ Os motivos zoomórficos representados nas placas de tear de Vila Nova de São Pedro (Azambuja, Portugal) Andrea Martins / César Neves / José M. Arnaud / Mariana Diniz

571 Arte Rupestre do Monte de Góios (Lanhelas, Caminha). Síntese dos resultados dos trabalhos efectuados em 2007-2009 Mário Varela Gomes

599 Gravuras rupestres de barquiformes no Monte de S. Romão, Guimarães, Noroeste de Portugal Daniela Cardoso

613 Círculos segmentados gravados na Bacia do Rio Lima (Noroeste de Portugal): contributos para o seu estudo Diogo Marinho / Ana M.S. Bettencourt / Hugo Aluai Sampaio

631 Equídeos gravados no curso inferior do Rio Mouro, Monção (NW Portugal). Análise preliminar Coutinho, L.M. / Bettencourt, A.M.S / Sampaio, Hugo A.S

645 Paletas na Arte Rupestre do Noroeste de Portugal. Inventário preliminar Bruna Sousa Afonso / Ana M. S. Bettencourt / Hugo A. Sampaio 


\section{Pré-História}

661 O projeto Miño/Minho: balanço de quatro anos de trabalhos arqueológicos Sérgio Monteiro-Rodrigues / João Pedro Cunha-Ribeiro / Eduardo Méndez-Quintas / Carlos Ferreira / Pedro Xavier / José Meireles / Alberto Gomes / Manuel Santonja / Alfredo Pérez-González

677 A ocupação paleolítica da margem esquerda do Baixo Minho: a indústria lítica do sítio de Pedreiras 2 (Monção, Portugal) e a sua integração no contexto regional Carlos Ferreira / João Pedro Cunha-Ribeiro / Sérgio Monteiro-Rodrigues / Eduardo Méndez-Quintas / Pedro Xavier / José Meireles / Alberto Gomes / Manuel Santonja / Alfredo Pérez-González

693 O sítio acheulense do Plistocénico médio da Gruta da Aroeira Joan Daura / Montserrat Sanz / Filipa Rodrigues / Pedro Souto / João Zilhão

703 As sociedades neandertais no Barlavento algarvio: modelos preditivos com recurso aos SIG

Daniela Maio

715 A utilização de quartzo durante o Paleolítico Superior no território dos vales dos rios Vouga e Côa

Cristina Gameiro / Thierry Aubry / Bárbara Costa / Sérgio Gomes / Luís Luís / Carmen Manzano / André Tomás Santos

733 Uma perspetiva diacrónica da ocupação do concheiro do Cabeço da Amoreira (Muge, Portugal) a partir da tecnologia lítica Joana Belmiro / João Cascalheira / Célia Gonçalves

745 Novos dados sobre a Pré-história Antiga no concelho de Palmela. A intervenção arqueológica no sítio do Poceirão I

Michelle Teixeira Santos

757 Problemas em torno de Datas Absolutas Pré-Históricas no Norte do Alentejo Jorge de Oliveira

771 Povoamento pré-histórico nas áreas montanhosas do NO de Portugal: o Abrigo 1 de Vale de Cerdeira Pedro Xavier / José Meireles / Carlos Alves

783 Apreciação do povoamento do Neolítico Inicial na Baixa Bacia do Douro. A Lavra I (Serra da Aboboreira) como caso de estudo Maria de Jesus Sanches

797 O Processo de Neolitização na Plataforma do Mondego: os dados do Sector C do Outeiro dos Castelos de Beijós (Carregal do Sal)

João Carlos de Senna-Martinez / José Manuel Quintã Ventura / Andreia Carvalho / Cíntia Maurício

823 Novos trabalhos na Lapa da Bugalheira (Almonda, Torres Novas) Filipa Rodrigues / Pedro Souto / Artur Ferreira / Alexandre Varanda / Luís Gomes / Helena Gomes / João Zilhão

837 A pedra polida e afeiçoada do sítio do Neolítico médio da Moita do Ourives (Benavente, Portugal)

César Neves

857 Casal do Outeiro (Encarnação, Mafra): novos contributos para o conhecimento do povoamento do Neolítico final na Península de Lisboa.

Cátia Delicado / Carlos Maneira e Costa / Marta Miranda / Ana Catarina Sousa

873 Stresse infantil, morbilidade e mortalidade no sítio arqueológico do Neolítico Final/ Calcolítico ( $4^{\circ}$ e $3^{\circ}$ milénio a.C.) do Monte do Carrascal 2 (Ferreira do Alentejo, Beja) Liliana Matias de Carvalho / Sofia N. Wasterlain 
885 Come together: O Conjunto Megalítico das Motas (Monção, Viana do Castelo) e as expressões Campaniformes do Alto Minho Ana Catarina Basílio / Rui Ramos

899 Trabalhos arqueológicos no sítio Calcolítico da Pedreira do Poio Carla Magalhães / João Muralha / Mário Reis / António Batarda Fernandes

913 O sítio arqueológico de Castanheiro do Vento. Da arquitectura do sítio à arquitectura de um território João Muralha Cardoso

925 Estudo zooarqueológico das faunas do Calcolítico final de Vila Nova de São Pedro (Azambuja, Portugal): Campanhas de 2017 e 2018 Cleia Detry / Ana Catarina Francisco / Mariana Diniz / Andrea Martins / César Neves / José Morais Arnaud

943 As faunas depositadas no Museu Arqueológico do Carmo provenientes de Vila Nova de São Pedro (Azambuja): as campanhas de 1937 a 1967 Ana Catarina Francisco / Cleia Detry / César Neves / Andrea Martins / Mariana Diniz / José Morais Arnaud

959 Análise funcional de material lítico em sílex do castro de Vila Nova de S. Pedro (Azambuja, Portugal): uma primeira abordagem Rafael Lima

971 O recinto da Folha do Ouro 1 (Serpa) no contexto dos recintos de fossos calcolíticos alentejanos

António Carlos Valera / Tiago do Pereiro / Pedro Valério / António M. Monge Soares

\section{Proto-História}

987 Produção de sal marinho na Idade do Bronze do noroeste Português. Alguns dados para uma reflexão

Ana M. S. Bettencourt / Sara Luz / Nuno Oliveira / Pedro P. Simões / Maria Isabel C. Alves / Emílio Abad-Vidal

1001 A estátua-menir do Pedrão ou de São Bartolomeu do Mar (Esposende, noroeste de Portugal) no contexto arqueológico da fachada costeira de entre os rios Neiva e Cávado Ana M. S. Bettencourt / Manuel Santos-Estévez / Pedro Pimenta Simões / Luís Gonçalves

1015 O Castro do Muro (Vandoma/Baltar, Paredes) - notas para uma biografia de ocupação da Idade do Bronze à Idade Média

Maria Antónia D. Silva / Ana M. S. Bettencourt / António Manuel S. P. Silva / Natália Félix

1031 Do Bronze Final à Idade Média - continuidades e hiatos na ocupação de Povoados em Oliveira de Azeméis João Tiago Tavares / Adriaan de Man

1041 As faunas do final da Idade do Bronze no Sul de Portugal: leituras desde o Outeiro do Circo (Beja)

Nelson J. Almeida / Íris Dias / Cleia Detry / Eduardo Porfírio / Miguel Serra

1055 A Espada do Monte das Oliveiras (Serpa) - uma arma do Bronze Pleno do Sudoeste Rui M. G. Monge Soares / Pedro Valério / Mariana Nabais / António M. Monge Soares

1065 São Julião da Branca (Albergaria-a-Velha) - Investigação e valorização de um povoado do Bronze Final

António Manuel S. P. Silva / Paulo A. P. Lemos / Sara Almeida e Silva / Edite Martins de Sá

1083 Do castro de S. João ao Mosteiro de Santa Clara: notícia de uma intervenção arqueológica, em Vila do Conde Rui Pinheiro 
1095 O castro de Ovil (Espinho), um quarto de século de investigação - resultados e questões em aberto

Jorge Fernando Salvador / António Manuel S. P. Silva

1111 O Castro de Salreu (Estarreja), um povoado proto-histórico no litoral do Entre Douro e Vouga

Sara Almeida e Silva / António Manuel S. P. Silva / Paulo A. P. Lemos / Edite Martins de Sá

1127 Castro de Nossa Senhora das Necessidades (Sernancelhe): uma primeira análise artefactual Telma Susana O. Ribeiro

${ }_{1141}$ A cividade de Bagunte. O estado atual da investigação Pedro Brochado de Almeida

1153 Zoomorfos na cerâmica da Idade do Ferro no NW Peninsular: inventário, cronologias e significado Nuno Oliveira / Cristina Seoane

1163 Vasos gregos em Portugal: diferentes maneiras de contar a história do intercâmbio cultural na Idade do Ferro

Daniela Ferreira

1175 Os exotica da necrópole da Idade do Ferro do Olival do Senhor dos Mártires (Alcácer do Sal) no seu contexto regional

Francisco B. Gomes

\section{Antiguidade Clássica e Tardia}

1191 O uso de madeira como combustível no sítio da Quinta de Crestelos (Baixo Sabor): da Idade do Ferro à Romanização Filipe Vaz / João Tereso / Sérgio Simões Pereira / José Sastre / Javier Larrazabal Galarza / Susana Cosme / José António Pereira / Israel Espi

1207 Cultivos de Época Romana no Baixo Sabor: continuidade em tempos de mudança? João Pedro Tereso / Sérgio Simões Pereira / Filipe Santos / Luís Seabra / Filipe Vaz

1221 A casa romana na Hispânia: aplicação dos modelos itálicos nas províncias ibéricas Fernanda Magalhães / Diego Machado / Manuela Martins

1235 As pinturas murais romanas da Rua General Sousa Machado, n. ${ }^{5}$ 1, Chaves José Carvalho

1243 Trás do Castelo (Vale de Mir, Pegarinhos, Alijó) - Uma exploração agrícola romana do Douro

Tony Silvino / Pedro Pereira

1255 A sequência de ocupação no quadrante sudeste de Bracara Augusta: as transformações de uma unidade doméstica Lara Fernandes / Manuela Martins

1263 Os Mosaicos com decoração geométrica e geométrico-vegetalista dos sítios arqueológicos da área do Conuentus Bracaraugustanus. Novas abordagens quanto à conservação, restauro, decoração e datação Maria de Fátima Abraços / Licínia Wrench

1277 “Casa Romana” do Castro de São Domingos (Cristelos, Lousada): Escavação, Estudo e Musealização Paulo André de P. Lemos

1291 A arqueobotânica no Castro de Guifões (Matosinhos, Noroeste de Portugal): O primeiro estudo carpológico

Luís Seabra / Andreia Arezes / Catarina Magalhães / José Varela / João Pedro Tereso 
1305 Um Horreum Augustano na Foz do Douro (Monte do Castelo de Gaia, Vila Nova de Gaia) Rui Ramos

1311 Ponderais romanos na Lusitânia: padrões, formas, materiais e contextos de utilização Diego Barrios Rodríguez

1323 Um almofariz centro-itálico na foz do Mondego

Marco Penajoia

1335 Estruturas romanas de Carnide - Lisboa Luísa Batalha / Mário Monteiro / Guilherme Cardoso

1347 O contexto funerário do sector da "necrópole NO" da Rua das Portas de S. Antão (Lisboa): o espaço, os artefactos, os indivíduos e a sua interconectividade na interpretação do passado Sílvia Loja, José Carlos Quaresma, Nelson Cabaço, Marina Lourenço, Sílvia Casimiro, Rodrigo Banha da Silva, Francisca Alves-Cardoso

${ }_{1361}$ Povoamento em época Romana na Amadora - resultados de um projeto pluridisciplinar Gisela Encarnação / Vanessa Dias

1371 A Arquitectura Residencial em Mirobriga (Santiago do Cacém): contributo a partir de um estudo de caso Filipe Sousa / Catarina Felício

${ }_{1385}$ O fim do ciclo. Saneamento e gestão de resíduos nos edifícios termais de Mirobriga (Santiago do Cacém)

Catarina Felício / Filipe Sousa

1399 Balsa, Topografia e Urbanismo de uma Cidade Portuária Vítor Silva Dias / João Pedro Bernardes / Celso Candeias / Cristina Tété Garcia

1413 No Largo das Mouras Velhas em Faro (2017): novas evidências da necrópole norte de Ossonoba e da sua ocupação medieval Ricardo Costeira da Silva / Paulo Botelho / Fernando Santos / Liliana Nunes

1429 Instrumentos de pesca recuperados numa fábrica de salga em Ossonoba (Faro) Inês Rasteiro / Ricardo Costeira da Silva / Paulo Botelho

1439 A Necrópole Romana do Eirô, Duas Igrejas (Penafiel): intervenção arqueológica de 2016 Laura Sousa / Teresa Soeiro

1457 Ritual, descarte ou afetividade? A presença de Canis lupus familiaris na Necrópole Noroeste de Olisipo (Lisboa)

Beatriz Calapez Santos / Sofia Simões Pereira / Rodrigo Banha da Silva / Sílvia Casimiro / Cleia Detry / Francisca Alves Cardoso

1467 Dinâmicas económicas em Bracara na Antiguidade Tardia Diego Machado / Manuela Martins / Fernanda Magalhães / Natália Botica

1479 Cerâmicas e Vidros da Antiguidade Tardia do Edifício sob a Igreja do Bom Jesus (Vila Nova de Gaia) Joaquim Filipe Ramos

1493 Novos contributos para a topografia histórica de Mértola no período romano e na Antiguidade Tardia Virgílio Lopes

\section{8. Época Medieval}

1511 Cerâmicas islâmicas no Garb setentrional "português": algumas evidências e incógnitas Constança dos Santos / Helena Catarino / Susana Gómez / Maria José Gonçalves / Isabel Inácio / Gonçalo Lopes / Jacinta Bugalhão / Sandra Cavaco / Jaquelina Covaneiro / Isabel Cristina Fernandes / Ana Sofia Gomes 
1525 Contributo para o conhecimento da cosmética islâmica, em Silves, durante a Idade Média Rosa Varela Gomes

1537 Yábura e o seu território - uma análise histórico-arqueológica de Évora entre os séculos VIII-XII José Rui Santos

1547 A encosta sul do Castelo de Palmela - resultados preliminares da escavação arqueológica Luís Filipe Pereira / Michelle Teixeira Santos

1559 A igreja de São Lourenço (Mouraria, Lisboa): um conjunto de silos e de cerâmica medieval islâmica

Andreia Filipa Moreira Rodrigues

1571 O registo material de movimentações populacionais no Médio Tejo, durante os séculos XII-XIII. Dois casos de "sunken featured buildings", nos concelhos de Cartaxo e Torres Novas Marco Liberato / Helena Santos / Nuno Santos

1585 O nordeste transmontano nos alvores da Idade média. Notas para reflexão Ana Maria da Costa Oliveira

1601 Sepulturas escavadas na rocha do Norte de Portugal e do Vale do Douro: primeiros resultados do Projecto SER-NPVD

Mário Jorge Barroca / César Guedes / Andreia Arezes / Ana Maria Oliveira

1619 "Portucalem Castrum Novum" entre o Mediterrâneo e o Atlântico: o estudo dos materiais cerâmicos alto-medievais do arqueossítio da rua de D. Hugo, nํ. 5 (Porto) João Luís Veloso

1627 A Alta Idade Média na fronteira de Lafões: notas preliminares sobre a Arqueologia no Concelho de Vouzela

Manuel Luís Real / Catarina Tente

1641 Um conjunto cerâmico medieval fora de portas: um breve testemunho aveirense Susana Temudo

${ }_{1651}$ Os Lóios do Porto: uma perspetiva integrada no panorama funerário da Baixa Idade Média à Época Moderna em meios urbanos em Portugal

Ana Lema Seabra

1659 O Caminho Português Interior de Santiago como eixo viário na Idade Média Pedro Azevedo

1665 Morfologia Urbana: Um exercício em torno do Castelo de Ourém André Donas-Botto / Jaqueline Pereira

1677 Intervenção arqueológica na Rua Marquês de Pombal/Largo do Espírito Santo (Bucelas, Loures)

Florbela Estêvão / Nathalie Antunes-Ferreira / Dário Ramos Neves / Inês Lisboa

1691 O Cemitério Medieval do Poço do Borratém e a espacialidade funerária na cidade de Lisboa Inês Belém / Vanessa Filipe / Vasco Noronha Vieira / Sónia Ferro / Rodrigo Banha da Silva

1705 Um Espaço Funerário Conventual do séc. XV em Lisboa: o caso do Convento de São Domingos da Cidade Sérgio Pedroso / Sílvia Casimiro / Rodrigo Banha da Silva / Francisca Alves Cardoso

\section{9. Época Moderna e Contemporânea}

1721 Arqueologia Moderna em Portugal: algumas reflexões críticas em torno da quantificação de conjuntos cerâmicos e suas inferências históricas e antropológicas Rodrigo Banha da Silva / André Bargão / Sara da Cruz Ferreira

1733 Faianças de dois contextos entre os finais do século XVI e XVIII do Palácio dos Condes de Penafiel, Lisboa

Martim Lopes / Tomás Mesquita 
1747 Um perfil de consumo do século XVIII na foz do Tejo: O caso do Mercado da Ribeira, Lisboa Sara da Cruz Ferreira / Rodrigo Banha da Silva / André Bargão

1761 Os Cachimbos dos Séculos XVII e XVIII do Palácio Mesquitela e Convento dos Inglesinhos (Lisboa)

Inês Simão / Marina Pinto / João Pimenta / Sara da Cruz Ferreira / André Bargão / Rodrigo Banha da Silva

1775 "Tomar os fumos da erua que chamão em Portugal erua sancta». Estudo de Cachimbos provenientes da Rua do Terreiro do Trigo, Lisboa

Miguel Martins de Sousa / José Pedro Henriques / Vanessa Galiza Filipe

1787 Cachimbos de Barro Caulínitico da Sé da Cidade Velha (República de Cabo Verde)

Rodrigo Banha da Silva / João Pimenta / Clementino Amaro

1801 Algumas considerações sobre espólio não cerâmico recuperado no Largo de Jesus (Lisboa) Carlos Boavida

1815 Adereços de vidro, dos séculos XVI-XVIII, procedentes do antigo Convento de Santana de Lisboa (anéis, braceletes e contas)

Joana Gonçalves / Rosa Varela Gomes / Mário Varela Gomes

1837 Da ostentação, luxo e poder à simplicidade do uso quotidiano: arqueologia e simbologia de joias e adornos da Idade Moderna Portuguesa Jéssica Iglésias

1849 Os amuletos em Portugal - dos objetos às superstições: o coral vermelho Alexandra Vieira

1865 Cerâmicas de Vila Franca de Xira nos séculos XV e XVI Eva Pires

1879 «Não passa por teu o que me pertence». Marcas de individualização associadas a faianças do Convento de Nossa Senhora de Aracoeli, Alcácer do Sal Catarina Parreira / Íris Fragoso / Miguel Martins de Sousa

1891 Cerâmica de Leiria: alguns focos de produção

Jaqueline Pereira / André Donas-Botto

1901 Os Fornos na Rua da Biquinha, em Óbidos Hugo Silva / Filipe Oliveira

1909 A casa de Pêro Fernandes, contador dos contos de D. Manuel I: o sítio arqueológico da Silha do Alferes, Seixal (século XVI) Mariana Nunes Ferreira

1921 O Alto da Vigia (Sintra) e a vigilância e defesa da costa Alexandre Gonçalves / Sandra Santos

1937 O contexto da torre sineira da Igreja de Santa Maria de Loures Paulo Calaveira / Martim Lopes

1949 A Necrópole do Hospital Militar do Castelo de São Jorge e as práticas funerárias na Lisboa de Época Moderna Susana Henriques / Liliana Matias de Carvalho / Ana Amarante / Sofia N. Wasterlain

1963 SAND - Sarilhos Grandes Entre dois Mundos: o adro da Igreja e a Paleobiologia dos ossos humanos recuperados

Paula Alves Pereira / Roger Lee Jesus / Bruno M. Magalhães

1975 Expansão urbana da vila de Cascais no século XVII e XVIII: a intervenção arqueológica na Rua da Vitória no 15 a 17

Tiago Pereira / Vanessa Filipe

1987 Novos dados para o conhecimento do Urbanismo de Faro em época Moderna Ana Rosa 
1995 Um exemplo de Arqueologia Urbana em Alcoutim: o Antigo Edifício dos CTT Marco Fernandes / Marta Dias / Alexandra Gradim / Virgílio Lopes / Susana Gómez Martínez

2007 Palácio dos Ferrazes (Rua das Flores/Rua da Vitória, Porto): a cocheira de Domingos Oliveira Maia

Francisco Raimundo

2021 As muitas vidas de um edifício urbano: História, Arqueologia e Antropologia no antigo Recreatório Paroquial de Penafiel Helena Bernardo / Jorge Sampaio / Marta Borges

2035 O convento de Nossa Senhora da Esperança de Ponta Delgada: o contributo da arqueologia para o conhecimento de um monumento identitário João Gonçalves Araújo / N’Zinga Oliveira

2047 Arqueologia na ilha do Corvo... em busca da capela de Nossa Senhora do Rosário Tânia Manuel Casimiro / José Luís Neto / Luís Borges / Pedro Parreira

2059 Perdidos à vista da Costa. Trabalhos arqueológicos subaquáticos na Barra do Tejo Jorge Freire / José Bettencourt / Augusto Salgado

2071 Arqueologia marítima em Cabo Verde: enquadramento e primeiros resultados do projecto CONCHA

José Bettencourt / Adilson Dias / Carlos Lima / Christelle Chouzenoux / Cristóvão Fonseca / Dúnia Pereira / Gonçalo Lopes / Inês Coelho / Jaylson Monteiro / José Lima / Maria Eugénia Alves / Patrícia Carvalho / Tiago Silva

2085 Trabalhos arqueológicos na Cidade Velha (Ribeira Grande de Santiago, Cabo Verde): reflexões sobre um projecto de investigação e divulgação patrimonial André Teixeira / Jaylson Monteiro / Mariana Mateus / Nireide Tavares / Cristovão Fonseca / Gonçalo C. Lopes / Joana Bento Torres / Dúnia Pereira / André Bargão / Aurélie Mayer / Bruno Zélie / Carlos Lima / Christelle Chouzenoux / Inês Henriques / Inês Pinto Coelho / José Lima / Patrícia Carvalho / Tiago Silva

2103 A antiga fortificação de Quelba / Khor Kalba (E.A.U.). Resultados de quatro campanhas de escavações, problemáticas e perspectivas futuras Rui Carita / Rosa Varela Gomes / Mário Varela Gomes / Kamyar Kamyad

2123 Colónias para homens novos: arqueologia da colonização agrária fascista no noroeste ibérico Xurxo Ayán Vila / José Mạ . Señorán Martín 


\title{
ÁREAS DE POTENCIAL ARQUEOLÓGICO NA REGIÃO DO MÉDIO TEJO: MODELO ESPACIAL PREDITIVO
}

\author{
Rita Ferreira Anastácio ${ }^{1}$, Ana Filipa Martins ${ }^{2}$, Luiz Oosterbeek ${ }^{3}$
}

\begin{abstract}
RESUMO
Este artigo apresenta os resultados da construção de um Modelo Espacial Preditivo Arqueológico baseado na análise de um conjunto de variáveis.

O objetivo principal deste estudo para a Região do Médio Tejo é a identificação de áreas de potencial arqueológico para prospeção arqueológica, ou seja, áreas que apresentam uma maior probabilidade de ocorrência de novos sítios, através da aplicação de modelos espaciais preditivos, partindo de uma base de dados geográfica de sítios arqueológicos compilada e atualizada nas suas cronologias várias, e modelada através de Sistemas de Informação Geográfica, no quadro do projeto de investigação MTAS, apoiado pela FCT.

Assim, através de uma metodologia essencialmente estatística, descritiva e univariada e utilizando dois métodos - o método da adição binária e o método dos pesos - foram obtidas as áreas com potencialidade de prospeção de novos sítios arqueológicos, para a região do Médio Tejo.

Palavras-chave: Modelo Espacial Preditivo, Sítios Arqueológicos, Sistemas de Informação Geográfica, Áreas de Potencial Arqueológico.
\end{abstract}

\begin{abstract}
This article presents the results of the construction of an Archaeological Predictive Spatial Model based on the analysis of a set of variables.

The main objective of this study is to identify areas of archaeological potential for archaeological exploration, for the Médio Tejo Region. This areas are more likely to occur in new sites, through the application of predictive spatial models, starting from a base of geographic data from archaeological sites compiled and updated in their various chronologies, and modeled through Geographic Information Systems, within the framework of the MTAS research project, supported by FCT.

Thus, through an essentially statistical, descriptive and univariate methodology and using two methods - the method of binary addition and the method of weights - the areas with potential for prospecting new archaeological sites were obtained for the Médio Tejo Region.

Keywords: Predictive Spatial Model, Archaeological Sites, Geographic Information Systems, Areas of Archaeological Potential.
\end{abstract}

\section{INTRODUÇÃO}

A distribuição dos vestígios arqueológicos no espaço não é aleatória. Está inerente a um padrão influenciado por vários fatores, tais como: o comportamento das comunidades humanas do passado, os processos naturais e ambientais, e a ação humana na paisagem. De um modo geral, parte-se do princípio de que o comportamento humano no passado produz padrões na cultura material e na paisagem, que embora possam ser alterados por processos naturais e pela contínua ação antrópica, encontram-se ainda hoje em dia representados na paisagem (Warren et al., 200o).

\footnotetext{
1. Instituto Politécnico de Tomar, Centro de Geociências da Universidade de Coimbra; rfanastacio@ipt.pt.

2. Instituto Politécnico de Tomar.

3. Instituto Politécnico de Tomar, Centro de Geociências da Universidade de Coimbra.
} 
O desenvolvimento de modelos preditivos é uma das mais frequentes aplicações em Sistemas de Informação Geográfica, no âmbito da investigação arqueológica (Wheatley et al., 2002, Kvamme, 2006), baseando-se em três pressupostos principais: (1) a escolha do local influenciada por elementos ambientais, naturais e físicos favoráveis à fixação humana, criando um padrão espacial específico; (2) as condições do passado que condicionaram a fixação humana encontrarem-se, direta ou indiretamente, representadas na paisagem atual; (3) os sítios que se localizam numa mesma área de características ambientais (físicas e naturais) análogas têm tendência a depender de igual forma do meio envolvente (Warren et al., 2000; Bona, 2000).

A previsão é a componente central da análise espacial e o objetivo da modelação preditiva é gerar um modelo espacial que tenha implicações preditivas para observações futuras. Em contextos arqueológicos, significa que o objetivo é construir uma hipótese sobre a localização de vestígios arqueológicos que possa ser usada para prever a localização de locais que ainda não foram observados (Wheatley et al., 2002). O desenvolvimento dos modelos preditivos na Arqueologia, tem vindo a permitir dotar os arqueólogos com informações sobre a potencial distribuição dos sítios arqueológicos, possibilitando otimizar o trabalho de campo, gestão de recursos culturais e tomada de decisões sobre a preservação, contribuindo para uma gestão do território mais eficaz. Os métodos mais comuns utilizados são o método da intersecção e o método dos pesos. O primeiro método assenta sobre o princípio que todas as variáveis independentes contribuem de forma igual para a determinação do potencial de localização de um sítio arqueológico; enquanto que o segundo método considera que cada variável independente contribui com pesos diferentes sobre o potencial de localização de um sítio arqueológico. O peso de cada variável independente no modelo estima-se através da sua relação estatística com a localização de sítios arqueológicos conhecidos (Bona, 2000; Ebert, 200o).

\section{ENQUADRAMENTO GEOGRÁFICO DO MÉDIO TEJO}

A região do Médio Tejo, com cerca de 3.344,o km², localiza-se na região Centro de Portugal, abrangendo os concelhos de Abrantes, Alcanena, Constância, Entroncamento, Ferreira do Zêzere, Mação,
Ourém, Sardoal, Sertã, Tomar, Torres Novas, Vila de Rei e Vila Nova da Barquinha. Em 2008 foi constituída a Comunidade Intermunicipal do Médio Tejo (CIMT) com o intuito de promover o desenvolvimento equilibrado e sustentável do seu território de intervenção, com base no planeamento estratégico regional e o apoio às autarquias dos concelhos que a constituem (Figura 1).

Esta região caracteriza-se por classes de altimetria que vão até pouco mais de $1000 \mathrm{~m}$ e de uma forma geral as altitudes predominantes situam-se entre os $50 \mathrm{~m}$ e os $400 \mathrm{~m}$. A sudoeste, nos concelhos de Alcanena, Ourém de Torres Novas e a nordeste, no concelho da Sertã são onde se encontram as altitudes mais elevadas, acima dos $1000 \mathrm{~m}$, correspondendo ao maciço calcário estremenho (serras de Aire e Candeeiros). Os Concelhos de Ferreira do Zêzere, Mação e Vila de Rei apresentam situações pontuais de altitudes entre 400 e $600 \mathrm{om}$. A sul encontra-se as áreas aplanadas correspondentes à bacia aluvionar do rio Tejo abrangendo os concelhos Abrantes, Constância, Tomar, Torres Novas e Vila Nova da Barquinha, com altitudes baixas que não ultrapassam os 50 metros.

Esta região apresenta uma extensa rede hidrográfica e está incluída praticamente na sua totalidade na Região Hidrográfica do Tejo, nomeadamente na margem direita do rio Tejo, onde são afluentes do Tejo Superior as sub-bacias dos rios Ocreza e Zêzere (que por sua vez tem como afluente o Rio Nabão), e do Tejo Inferior Alviela e Almonda.

\section{METODOLOGIA}

Um modelo preditivo pode ser considerado como um exemplo de modelação empírica, em que se parte do estudo da relação existente entre os fatores (ou variáveis) utilizados na análise, baseado nos conjuntos de valores conhecidos para cada um deles, procura estimar o comportamento das relações entre esses mesmos fatores no restante espaço da área. O modelo preditivo é constituído por 3 componentes: os dados ou informação pré-conhecida; o processo ou método de extrapolação e o resultado (Ebert, 200o; p. 3; Hatzinikolaou, 2006).

No caso da aplicação à investigação arqueológica, estes modelos partem da análise de características de implantação de sítios arqueológicos e, estabelecendo uma relação entre essas características, tenta estimar de que forma influenciaram a localização de cada sí- 
tio. Porque essa localização depende da relação com as características do local, pode-se definir de forma genérica uma função que traduz essa relação.

(1)Considerando que corresponde à localização de sítios arqueológicos e que está dependente da sua relação com múltiplas variáveis que condicionam a localização. Diz-se que a primeira é uma variável dependente e as restantes são variáveis independentes. Estas podem ser de natureza ambiental, como a altimetria e suas derivadas declives e orientação das encostas, os tipos de solo ou a proximidade de recursos hídricos; ou de ordem cultural/social, nomeadamente a localização de exploração mineiras ou a distância entre povoados (Ebert, 200o).

$\mathrm{O}$ processo de relacionar as características de implantação por forma a determinar a potencial existência de novos sítios pode ser alcançado de formas distintas, como o demonstra a inúmera bibliografia existente sobre a utilização de modelos preditivos em Arqueologia: assentando maioritariamente sobre métodos quantitativos de tratamento dos dados, abrangem técnica tão distintas como a regressão linear ou redes neuronais ou, ainda, a utilização de fuzzy logic (Hatzinikolaou, 2006). Os métodos mais comuns (Bona, 200o; Ebert, 200o) são:

- Método da interseção: este método baseia-se na sobreposição binária das variáveis independentes e assenta no princípio de que todas as variáveis contribuem de forma igual para determinação do potencial de localização de um sítio arqueológico, para cada ponto da área em estudo.

- Método dos pesos: ao contrário do anterior, este método assume que cada característica contribui de forma distinta e com pesos diferentes sobre o potencial de localização de um sítio arqueológico. O peso de cada variável independente no modelo estima-se através da sua relação estatística com a localização de sítios arqueológicos conhecidos. Por permitir que as características tenham impactos distintos na determinação do resultado final do modelo, pode-se considerar este método mais realista que $o$ anterior.

Para a construção a base de dados geográfica de apoio à modelação em SIG consideraram-se as seguintes variáveis: como variável dependente a informação sobre sítios arqueológicos, que inclui a sua localização, designação, tipologia e cronologia; como variáveis independentes as seguintes variáveis com características que poderão ter influenciado a fixação do homem nesta região (Kvamme, 2006; Ebert, 2000; Warren et al., 2000; Wheatley et al., 2002; Lock et al., 2006):

- Declive: por razões de fácil implantação de povoados bem como de atividades agrícolas, supõe-se que o declive dos terrenos poderá ter tido impacto na localização dos sítios arqueológicos.

- Distância a recursos hídricos: os recursos hídricos são de principal importância à fixação do homem. No presente estudo optou-se por incluir as linhas de água de maior expressão na região.

- Orientação de encostas: um fator geográfico que poderá ter influenciado a localização de sítios arqueológicos, nomeadamente em relação a proteção de ventos dominantes e maior exposição solar.

- Ocupação de solo: se os tipos de solo influenciam diretamente atividades como a exploração de recursos naturais, nomeadamente a agricultura, a atual ocupação do solo pode indiciar a propensão dos solos a essas mesmas atividades com base na sua utilização atual.

\section{DESENVOLVIMENTO DO MODELO PREDITIVO}

Com o intuito de simplificar a descrição do processo de desenvolvimento do modelo, optou-se por definir três etapas: a primeira etapa estruturar os dados; a segunda etapa classificar as variáveis independentes e finalmente, a terceira etapa proceder ao teste estatístico para identificar o nível de relação entre as variáveis independentes e a variável dependente.

\subsection{Preparação dos dados}

O primeiro passo modelo é a compilação e compatibilização dos dados que provêm de diferentes fontes, a partir do suporte inicial em formato tabular. A base de dados de partida é constituída por 614 sítios arqueológicos para a Região do Médio Tejo e inclui a sua designação, localização, tipologia e cronologia. Com base na sua localização (coordenadas) foi produzido o tema geográfico, recorrendo ao software ArcGis/ArcMap ESRI ${ }^{\circledR}$ usando a funcionalidade Create Feature Class From XY Table, que permite obter a representação geográfica dos dados baseada em coordenadas constantes em campos numéricos. Posteriormente, com o objetivo de testar o modelo, foram 
criados dois subconjuntos: 1) Sítios de modelo (composto por 491 sítios, cerca de 80\% dos sítios arqueológicos da base de dados), e 2) Sítios de teste (composto por 193 sítios, cerca de $20 \%$ dos sítios arqueológicos da base de dados).

Nesta fase procedeu-se à criação de temas geográficos derivados da Altimetria 1:2500o da cartografia militar, que permitiu construir o Modelo Digital de Terreno (MDT), designadamente o tema de declives e orientação das encostas (Figura 2).

Para preparar os dados geográficos relativo à variável recursos hídricos, foi determinada a distância a utilizar no modelo, usando um algoritmo baseado em custos associados ao percurso, tendo em conta o declive: o Cost Distance, que entra em linha de conta com eventuais obstáculos ou tão simplesmente com a dificuldade que se apresenta a um caminhante quando subindo ou descendo uma encosta comparado com o mesmo percurso num terreno plano (Figura 3).

Na maioria dos casos, o custo associado a este tipo de percursos em modelos de Arqueologia utiliza o declive como superfície de custo (Wheatley et al., 2002).

\subsection{Etapa 2 - Classificação das variáveis inde- pendentes}

Para proceder ao tratamento estatístico das variáveis independentes e testar a sua relação com a variável dependente, efetuou-se previamente a sua reclassificação (Figura 4).

O processo de reclassificação obedeceu a um conjunto de princípios em função de cada uma das variáveis que foram sobrepostos com os sítios arqueológicos do modelo:

1 - Agregação das categorias de ocupação do solo em sete classes simplificadas de ocupação do solo Corine Land Cover CLC20o6 (Anastácio, R. pp.113, 2016) de acordo com a Tabela 1.

O resultado da sua aplicabilidade deu origem a uma carta de ocupação do solo (Figura 5).

1 - Para a carta de declive e para o cálculo da distância aos rios foram geradas classes baseadas na distribuição estatística de cada variável (Santos, 2006). Para proceder a esta divisão foram utilizadas as funcionalidades de reclassificação que tem em consideração o desvio-padrão dessa distribuição: 1 Std Dev para o declive (Figura 6) e I/2 Std Dev para a distância aos rios (Figura 7).

1 - Para a orientação das encostas, como se trata de uma variável contínua cíclica $\left(\mathrm{o}^{\circ}-360^{\circ}\right)$, utilizaram-se os pontos cardeais e colaterais para a sua classificação: plano, N, NE, E, SE, S, SO, O, NO (Figura 8). Antes de proceder à análise estatística das variáveis, houve que transformar os diversos temas geográficos em formato vetorial para o formato raster, por forma a uniformizar a informação e proceder à análise espacial.

Por fim, procedeu-se ao cálculo estatístico da relação entre cada variável independente e a variável dependente, utilizando a funcionalidade Zonal Statistics as Table (Figura 9).

A informação recolhida tratou-se do número de células do raster de sítios arqueológicos ("sitios_Raster") que se encontravam dentro de cada classe das variáveis independentes (ocupação do solo, declive, orientação das encostas e distância a rios) eidentificar de que forma cada classe das variáveis independentes influencia a distribuição da variável dependente.

\subsection{Etapa 3-Teste às variáveis independentes}

$\mathrm{O}$ teste às variáveis independentes permite validar o pressuposto de que cada variável tem uma relação de não-aleatoriedade com a variável dependente, ou seja, que o facto de um sítio arqueológico se encontrar num determinado tipo de solo ou a uma curta distância de um rio não é casual. Caso este teste não consiga provar essa não-aleatoriedade, tal significa que a relação que está a ser testada é fraca, podendo-se considerar que a variável independente não teve influência na localização de sítios arqueológicos, pelo que deve ser excluída do modelo. No presente caso de estudo optou-se pela utilização do teste de Kolmogorov-Smirnov-largamente demonstrado em contextos semelhantes ao que se pretende criar (Kvamme, 2006; Ebert, 2000; Wheatley et al., 2002). O teste parte de duas hipóteses (Ebert, 200o):

$\mathrm{H}_{\mathrm{o}}$ - a distribuição da variável dependente é aleatória face à variável independente com que está a ser testada (também denominada hipótese nula).

$\mathrm{H}_{1}$ - a distribuição da variável dependente não é aleatória face à variável independente com que está a ser testada.

E compara a distribuição cumulativa de cada uma das variáveis. Caso a sua semelhança - designada $D_{\text {máx }}$ - seja inferior a um valor teórico $D_{\text {Ks }}$, então deve-se aceitar a hipótese $\mathrm{H}_{\mathrm{o}}$ e descartar a variável independente do modelo por se considerar que 
esta não teve influência na distribuição da variável dependente. Caso о valor $\mathrm{D}_{\text {кs }}$ seja excedido, rejeita-se $\mathrm{H}_{\mathrm{o}}$, aceitando-se como verdadeira a hipótese $\mathrm{H}_{1}$ e inclui-se a respetiva variável independente no modelo.

Para um nível de significância de o,05 a fórmula para o cálculo do valor teórico é, sendo n o número de sítios $(\mathrm{n}=491)$. Na Tabela 2 apresenta-se o resultado do teste para cada uma das variáveis.

Por comparação com o valor DKS, que para esse caso de estudo é de 0,061 para um nível de significância de 0,05 , deverão ser todas as variáveis independentes consideradas para a criação do modelo preditivo. É agora possível reescrever a equação (I) utilizando as variáveis independentes relevantes identificadas:

(2)

\section{Método 1 - Método da Sobreposição Binária}

No método da sobreposição binária, ou sobreposição booleana, os critérios são adaptados à lógica binária (o/1), em termos de aptidão, combináveis sequencialmente, através de operadores como a interseção e a união. Ou seja, consiste em reclassificar cada uma das variáveis em mapas temáticos binários (formato raster), e a cada célula atribuir um valor de o ou 1, em função da presença ou ausência de uma das características de localização dos sítios ( $\mathrm{o}=$ ausência, $1=$ presença). Asáreas que apresentam menos locais do que o esperado são classificadas com o e as áreas onde ocorrem locais ou mais do que o esperado com 1. Realizando esta operação para todas as variáveis, o modelo final é obtido adicionando os vários mapas binários. As células com maior agregação representam os pontos do mapa com maior probabilidade. A fórmula de criação de um modelo deste tipo pode-se apresentar da seguinte forma:

(3) Embora o modelo criado seja bastante prático a sua grande desvantagem é a inexistência de ponderação das variáveis. Desta forma, partindo da premissa que os fatores ambientais que influenciaram a localização dos sítios não tiveram o mesmo grau de importância, o passo seguinte foi calcular o peso de cada variável independente a ser incluída no modelo preditivo arqueológico. Ou seja, a cada mapa temático foi atribuído um peso diferente, uma vez que os fatores que influenciaram a localização dos sítios não possuem o mesmo grau de importância, não podendo consequentemente serem tratados igualitariamente.

\section{Método 2 - Método dos Pesos}

Este método utiliza uma função baseada no peso das variáveis, ou seja, parte do pressuposto que cada variável teve uma influência distinta na localização dos sítios arqueológicos.

O peso das variáveis independentes foi determinado com base na proporcionalidade da área em que a variável determinou a existência, ou seja, a área das classes em que o número de sítios observados não é nulo (Tabela 3).

(4)

\section{RESULTADOS}

Como todo o processo de cálculo se encontra assente em temas geográficos em formato raster, ao serem aplicadas as fórmulas apresentadas anteriormente ((3) e (4)) determina-se um valor específico para cada célula do modelo, usando a ferramenta Raster Calculator. Para cada célula da área de estudo obtém-se assim um valor que indica o maior ou menor potencial de existência de um sítio arqueológico nesse local.

Na Figura 10 apresenta-se o resultado do método da sobreposição binária para o total dos sítios arqueológicos em estudo, aplicando a equação (3).

Na Figura 11 apresenta-se o resultado do método dos pesos para o total dos sítios arqueológicos em estudo, aplicando a equação (4).

\subsection{Teste ao método 2}

Um modelo, qualquer que seja a realidade que ele procure representar e a forma como tenha sido construído, tem que ser testado antes de sobre ele ser depositado um nível de confiança suficiente que justifique e apoie a sua utilização (Kvamme, 2006). Havendo múltiplas formas de produzir esse teste, aquela que mais segurança garante é a utilização de um subconjunto de dados reais que tenha sido produzido aleatoriamente e omitido do universo na construção do modelo. Conforme anteriormente referido, foi inicialmente retirado um subconjunto ao universo de sítios arqueológicos utilizados que serviu para testar a capacidade de predição do modelo (Figura 12).

Para testar o método 2 (método de pesos), o mapa produzido foi reclassificado em três classes (limitadas por $50 \%, 80 \%$ e $100 \%$ do potencial de existência de sítios arqueológicos) após o que se determinaram as estatísticas do conjunto de sítios de 
teste para cada uma dessas áreas, usando mais uma vez a funcionalidade Zonal Statistics as Table (Tabela 4) e (Figura 13), de acordo com (Santos, 2006). O modelo identifica que cerca de dois terços da área ocupada por sítios submetidos ao teste numa região de potencial inferior a $50 \%$, sendo que os restantes um terço se encontra em áreas com um potencial superior a $50 \%$. Estes resultados podem dever-se a múltiplos fatores, que se podem englobar em duas classes, nomeadamente:

-Fatores de ordem interpretativa: na proximidade de recursos hídricos não é suficiente considerar-se a existência e proximidade de rios na modelação sem considerar a qualidade da sua água, sendo que esta poderá influenciar drasticamente os resultados do modelo (Wescott et al., 2000).

- Fatores de ordem técnica: o estudo apresentado não inclui certamente todos os critérios que levaram à fixação humana. Se os fatores ambientais são passíveis de estarem representados na cartografia utilizada, outras há de ordem social ou cultural que dificilmente serão recriáveis num modelo deste tipo, caso deles não exista relato histórico ou evidência arqueológica que os comprove. O tema de distância a recursos hídricos recriado neste estudo considera o declive como sendo o fator de custo na distância ponderada. No entanto, apesar desta ser uma simplificação comum neste tipo de modelos aplicados à Arqueologia, ela não tem em conta o tipo de terreno ou de coberto vegetal que atravessa no trajeto - considerando o mesmo declive, solos arenosos serão mais "difíceis" de atravessar do que terrenos de solo compacto, ou zonas de pastagem com mato rasteiro ou mesmo territórios atravessados por caminhos já existentes (Wheatley et al., 2002).

Estas considerações não devem, no entanto, ser consideradas limitativas, mas incentivadoras na continuidade do estudo agora desenvolvido. Como qualquer outro estudo em sistemas de informação geográfica, também um modelo preditivo deve ser constituído por um conjunto de iterações que validam, refinam e consolidam o sistema que está a ser implementado. Um modelo deverá ser visto como um processo evolutivo e interativo, em que novos dados poderão ser integrados em qualquer altura para otimizar e consolidar os resultados (Bona, 2000).

\section{CONSIDERAÇÕES FINAIS}

Pelo carácter geográfico-espacial dos dados com que lida, a Arqueologia, à semelhança do que outras ciências ou disciplinas vêm fazendo há já algumas décadas em Portugal, só poderá beneficiar da utilização de SIG. Este benefício manifestar-se-á não apenas na vertente de investigação arqueológica, mas igualmente na administração e planeamento de território e proteção de vestígios arqueológicos no terreno.

A utilização de um modelo preditivo só por si, isento de pensamento interpretativo e análise crítica, pode conduzir a erros, não devendo ser considerado mais que um meio de alcançar os fins a que a investigação arqueológica se propõe. O resultado de um modelo preditivo, utilizado sem critério, poderá conduzir à não execução de estudos ou investigação mais aprofundadas em zonas identificadas como de reduzida propensão à existência de sítios arqueológicos. Mais que o resultado de um modelo preditivo é a sua interpretação segundo o eixo arqueológico que pode traduzir a utilização destes meios em informação útil para o investigador. Conforme visível nos mapas resultantes do modelo criado, o nível baixo de potencialidade não invalida a existência de sítios arqueológicos, pelo que qualquer atividade que possa interferir com o subsolo não deverá ser menos cuidada nas medidas de prevenção e estudos de impacte a efetuar.

A aplicação de modelos preditivos assenta sobre condições que poderão ser julgadas falíveis. Nomeadamente, a investigação centra-se sobre os fatores ambientais que levaram à fixação do homem num ponto em particular da paisagem. Ignora assim que sistemas mais alargados se geram num território, nomeadamente que o povoado ou acampamento poderá constituir apenas um componente num sistema complexos, e que a relação entre vários povoados poderá ter levado, mais que qualquer fator externo, a uma nova fixação. Igualmente a qualidade dos dados poderá influenciar determinantemente os resultados de um modelo preditivo. No entanto, atendendo às considerações anteriormente abordadas, o modelo preditivo pode e deve constituir-se como mais uma ferramenta na investigação arqueológica, nomeadamente quando este considera a integração e exploração da paisagem pelo Homem no passado. De igual forma, quando administrando e gerindo os espaços e territórios 
de hoje, poderá o modelo preditivo ser utilizado como ferramenta auxiliar na interpretação do potencial cultural desses mesmos territórios. Um conhecimento da potencialidade da existência de sítios arqueológicos poderá minimizar a realização de atividades que possam interferir de forma irremediável com vestígios existentes no subsolo ou, quando tal não é possível, recomendar uma maior atenção e cuidados na realização de estudos que antecedam essas atividades.

\section{BIBLIOGRAFIA}

ANASTÁCIO, Rita (2016) - Da Gestão Do Património Cultural À Gestão Do Território Com Recurso A Tecnologias De Informação Geográfica: Contributos Metodológicos: Caso De Estudo - Região Do Médio Tejo. Tese de doutoramento em Quaternário Materiais e Culturas. Universidade de Trás-os-Montes e Alto Douro. Vila Real. (Documento policopiado).

BONA, Luke D. (200o) - Protecting Cultural Resources through Forest Management Planning in Ontario Using Archaeological Predictive Modeling. Practical Applications of GIS for Archaeologists - A Predictive Modeling Toolkit. Westcott, K. L.; Brandom J.. London: Taylor \& Francis.

EBERT, J. I. (2000) - The State of the Art in "Inductive" Predictive Modeling: Seven Big Mistakes (and Lots of Smaller Ones). Practical Applications of GIS for Archaeologists - A Predictive Modeling Toolkit. Westcott, L. K., Brandom J.. London: Taylor \& Francis.

HATZINIKOLAOU, Eugenia (2006) - Quantitative Methods in Archaeological Prediction: From Binary to Fuzzy Logic. GIS and Archaeological Site Location Modeling. Mehrer, M. W.; Westcott, K. L.. London New York: Taylor \& Francis.

LOCK, G.; HARRIS T. (2006) - Enhancing Predictive Archaelogical Modeling: Integrating Location, Landscape, and Culture. GIS and Archaeological Site Location Modeling. Mehrer, M. W.; Westcott, K. L.. London New York: Taylor \& Francis.

KVAMME, K. L. (2006) - There and Back Again: Revisiting Archaeological Locational Modeling. GIS and Archaeological Site Location Modeling. Mehrer, M. W.; Westcott, K. L.. London New York: Taylor \& Francis.

SANTOS, Pedro (2006) - Aplicações de Sistemas de Informação Geográfica em Arqueologia. Dissertação de mestrado. Instituto Superior de Estatística e Gestão de Informação da Universidade Nova de Lisboa.

WARREN R.; ASCHD. L. (200o) - A Predictive Model of Archaeological Site Location in the Eastern Prairie Peninsula. Practical Applications of GIS for Archaeologists - A Predictive Modeling Toolkit. Westcott, L. K., Brandom J.. London: Taylor \& Francis.
WESCOTT, K.; KUIPER, J. (200o) - Using a GIS to Model Prehistoric Site Distributions in the Upper Chesapeake Bay. Practical Applications of GIS for Archaeologists - A Predictive Modeling Toolkit. Westcott, L. K., Brandom J.. London: Taylor \& Francis.

WHEATLEY, David; GILLINGS Mark (2002) - Spatial tecnology and archaeology - The Archaeological Applications of GIS. London and New York: Taylor \& Francis. 

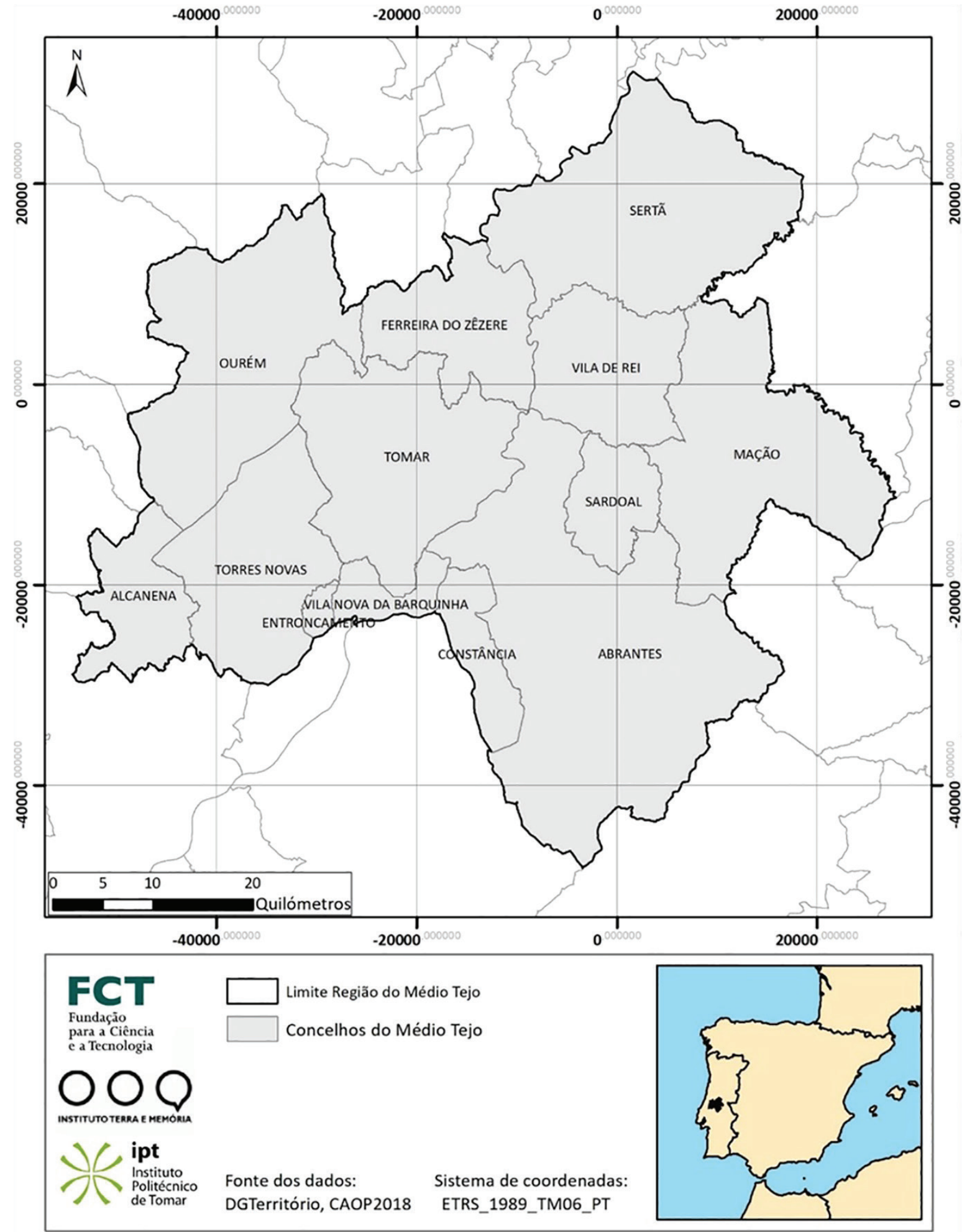

Figura 1 - Região do Médio Tejo: divisão administrativa. 


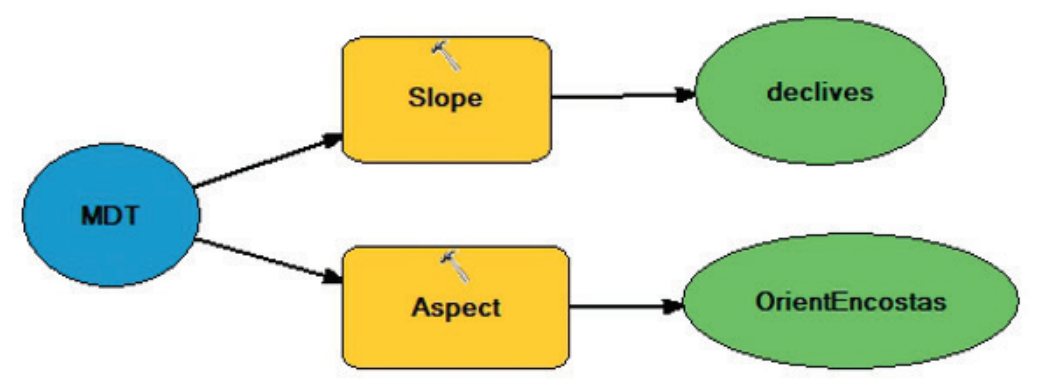

Figura 2 - Fluxograma funcional de obtenção da cartografia derivada do MDT.

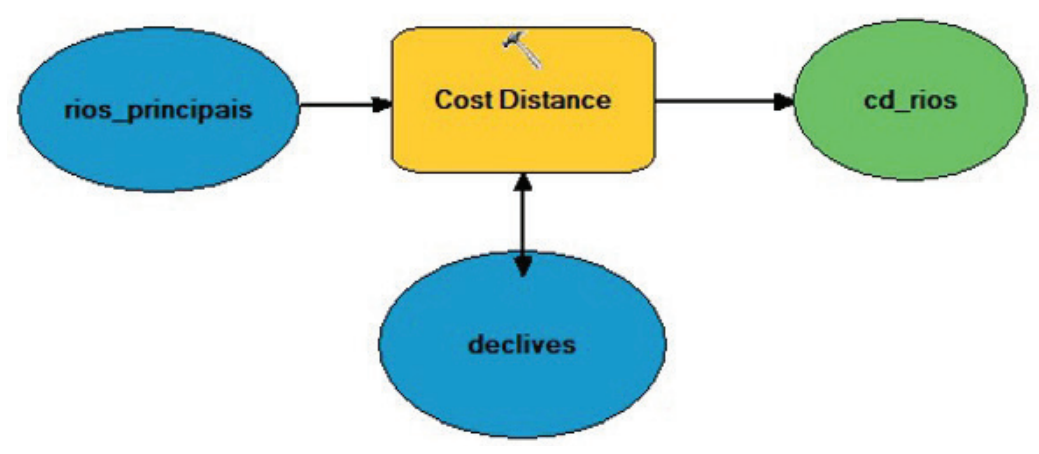

Figura 3 - Fluxograma funcional de cálculo da distância aos rios.

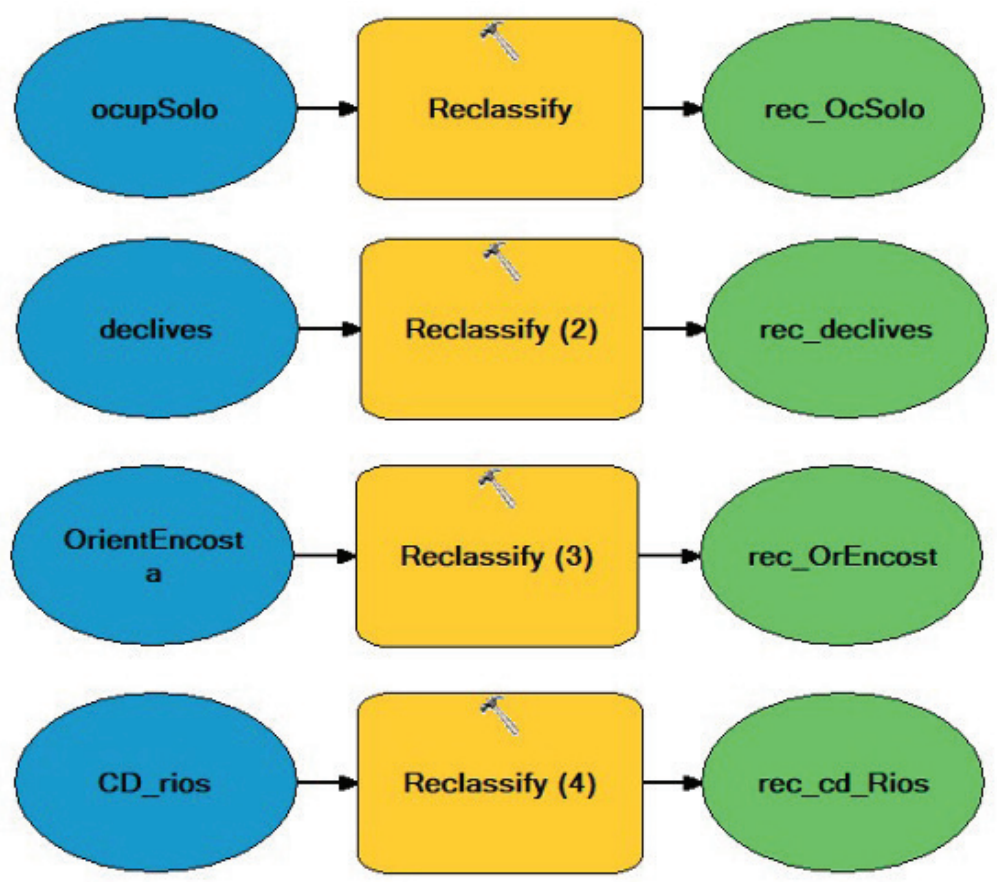

Figura 4 - Fluxograma funcional de reclassificação das variáveis independentes. 


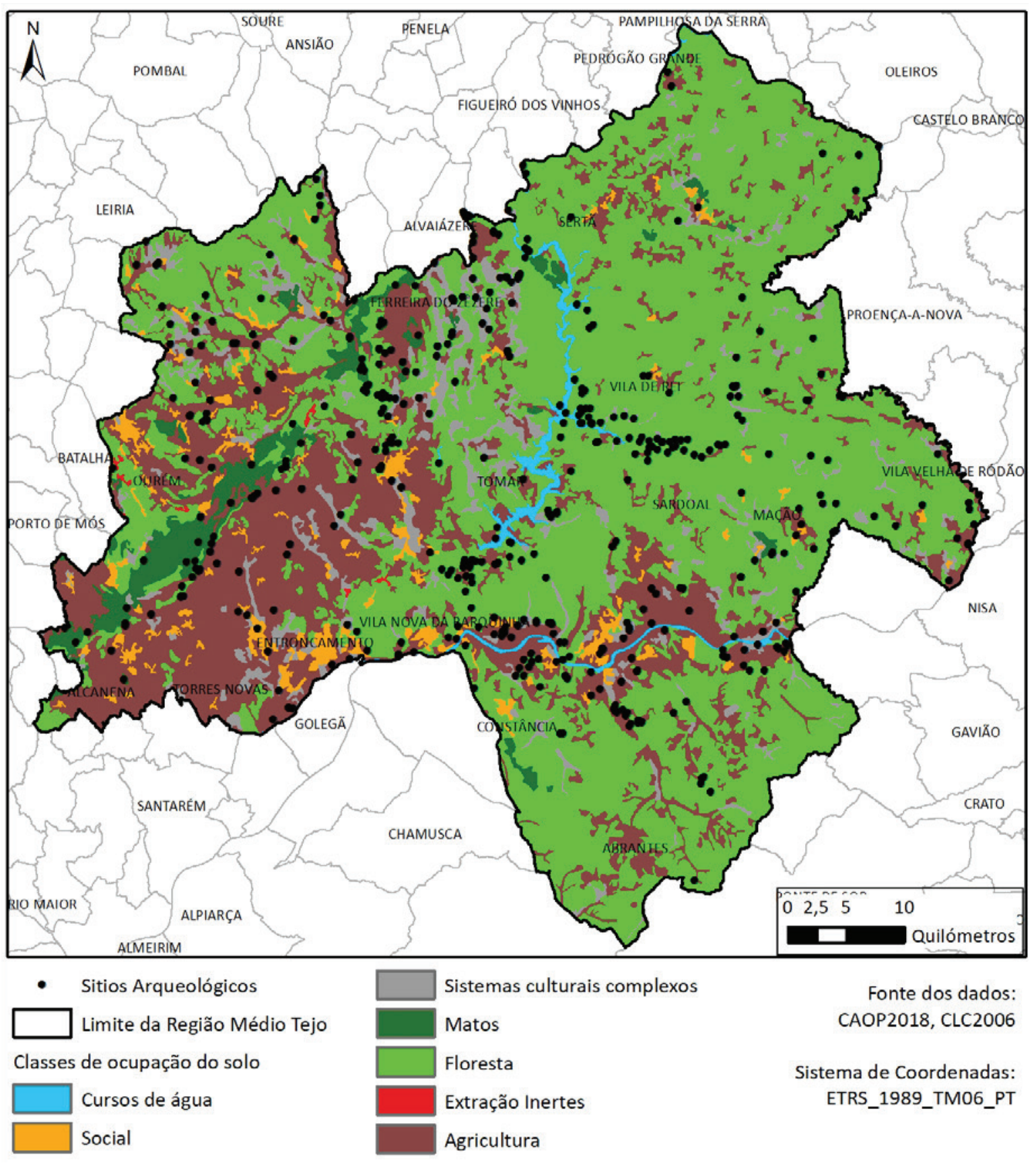

Figura 5-Carta de ocupação do solo. 


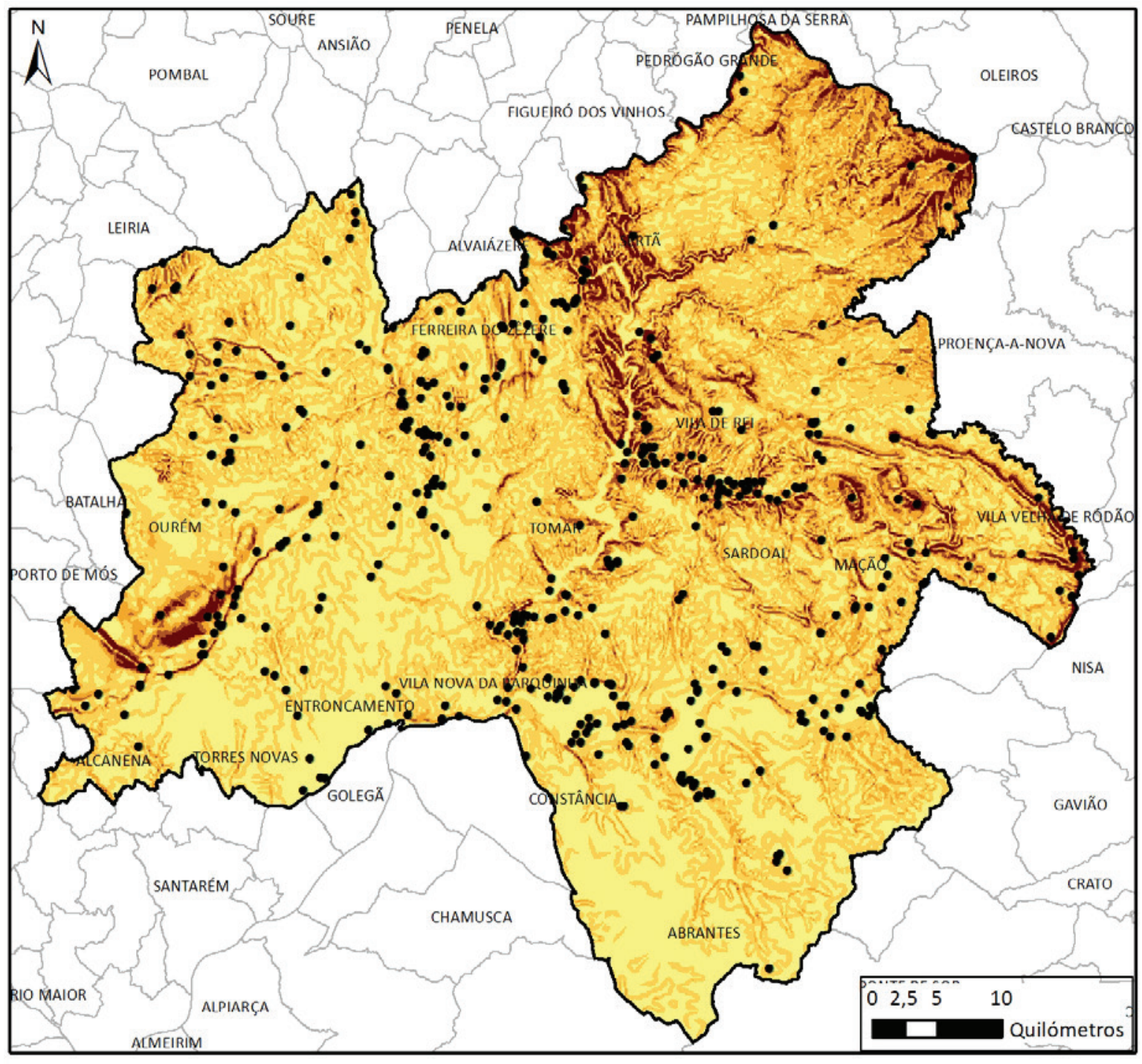

- Sitios Arqueológicos Limite da Região Médio Tejo
Classes de declive

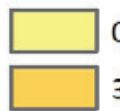

$0-3 \%$

$3 \%-11 \%$

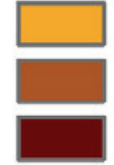

$11 \%-19 \%$

$19 \%-27 \%$

$27 \%-80 \%$
Fonte dos dados: CAOP2018

Sistema de Coordenadas: ETRS_1989_TM06_PT

Figura 6 - Carta de Declives. 


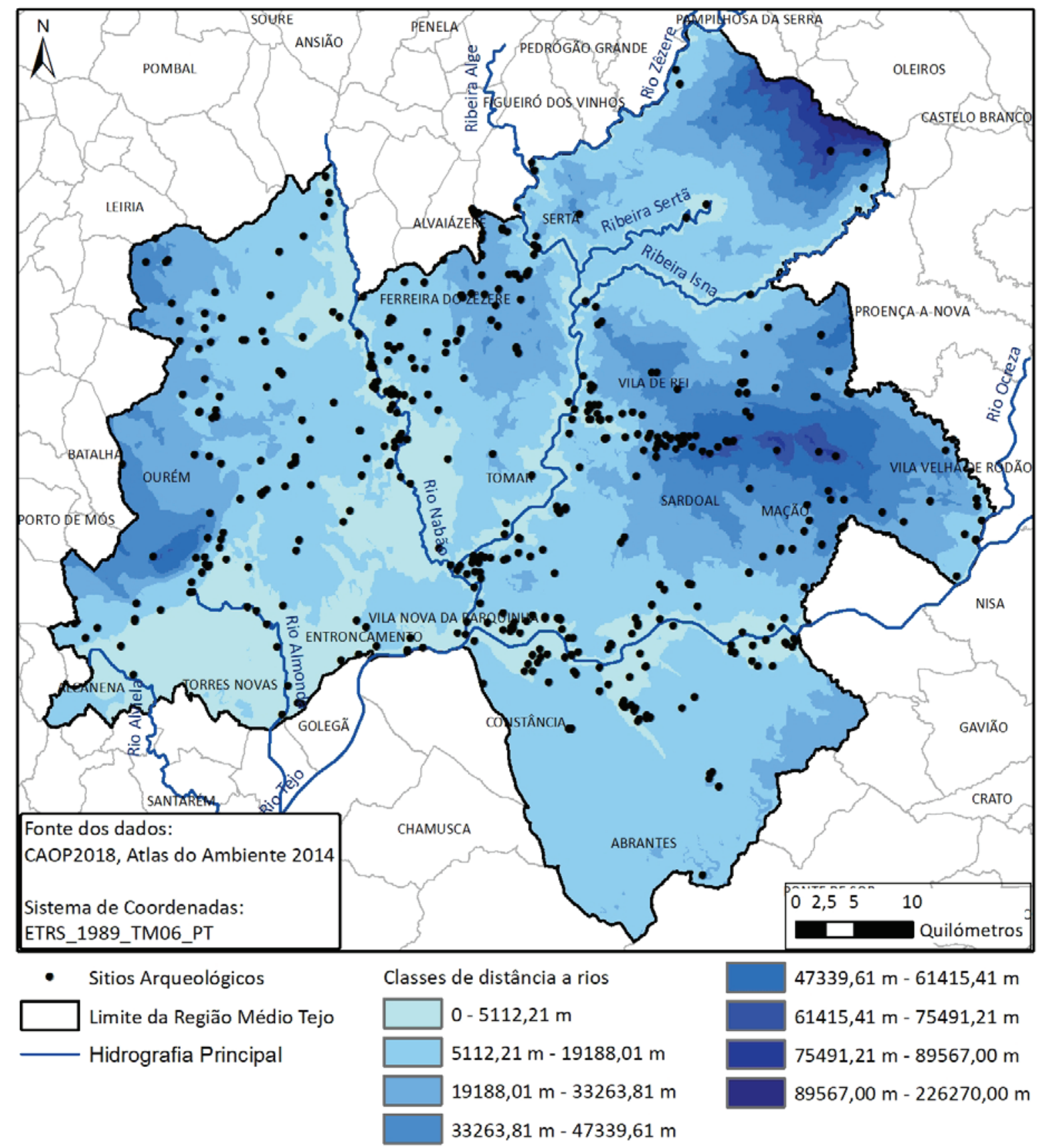

Figura 7-Hidrografia e distância a rios baseada em custos. 


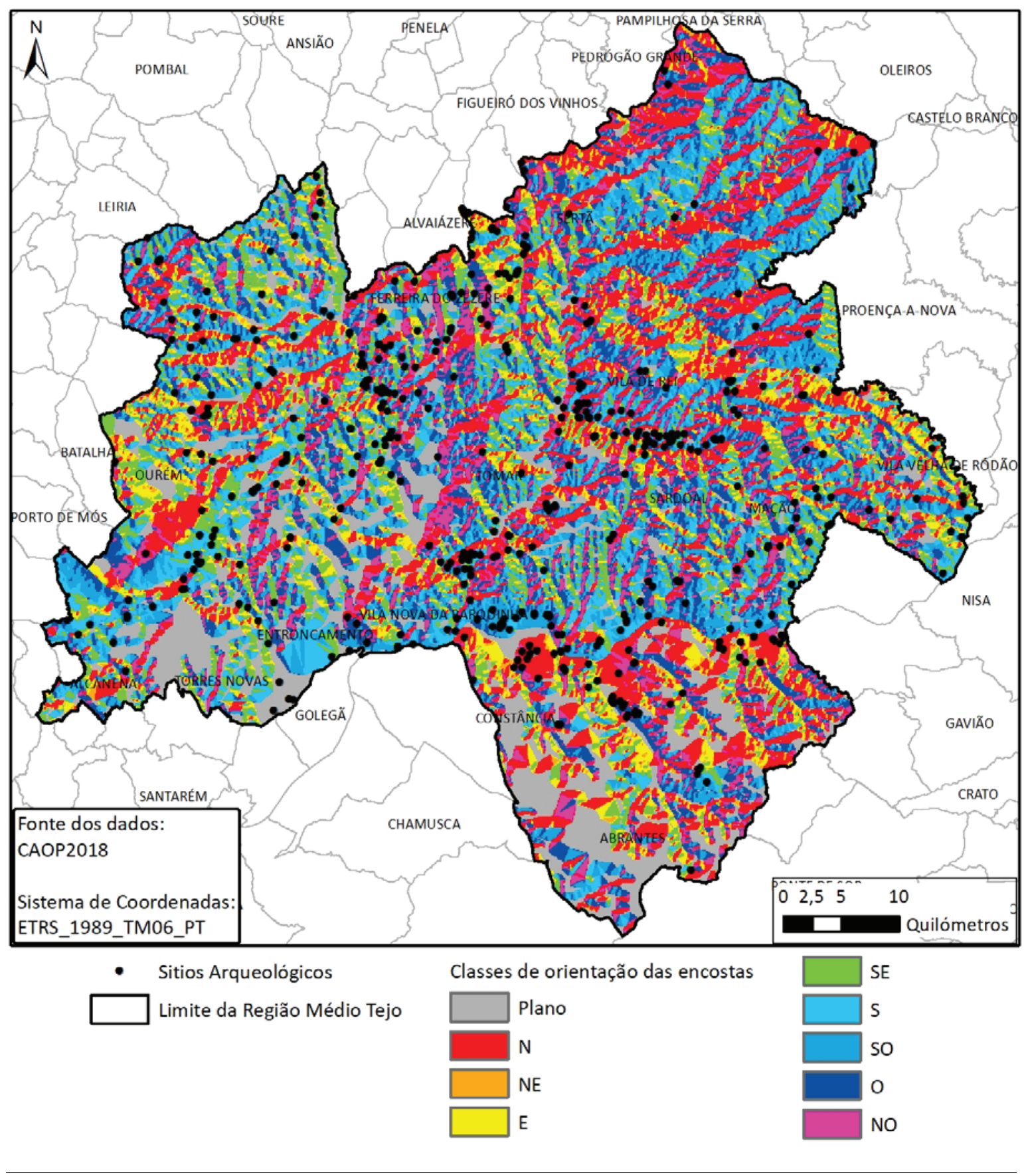

Figura 8 - Carta de orientação das encostas. 


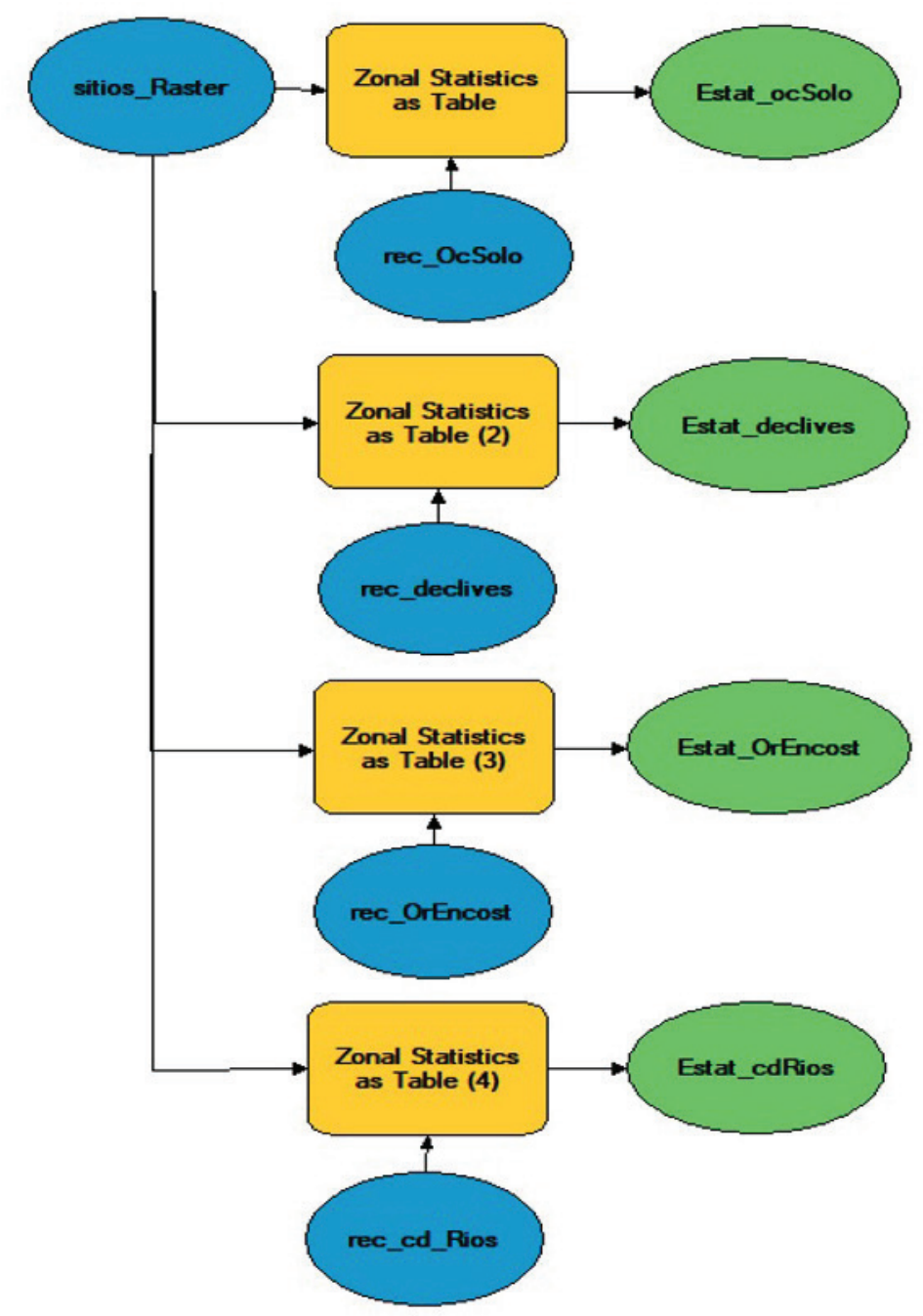

Figura 9 - Fluxograma funcional de obtenção de estatísticas. 


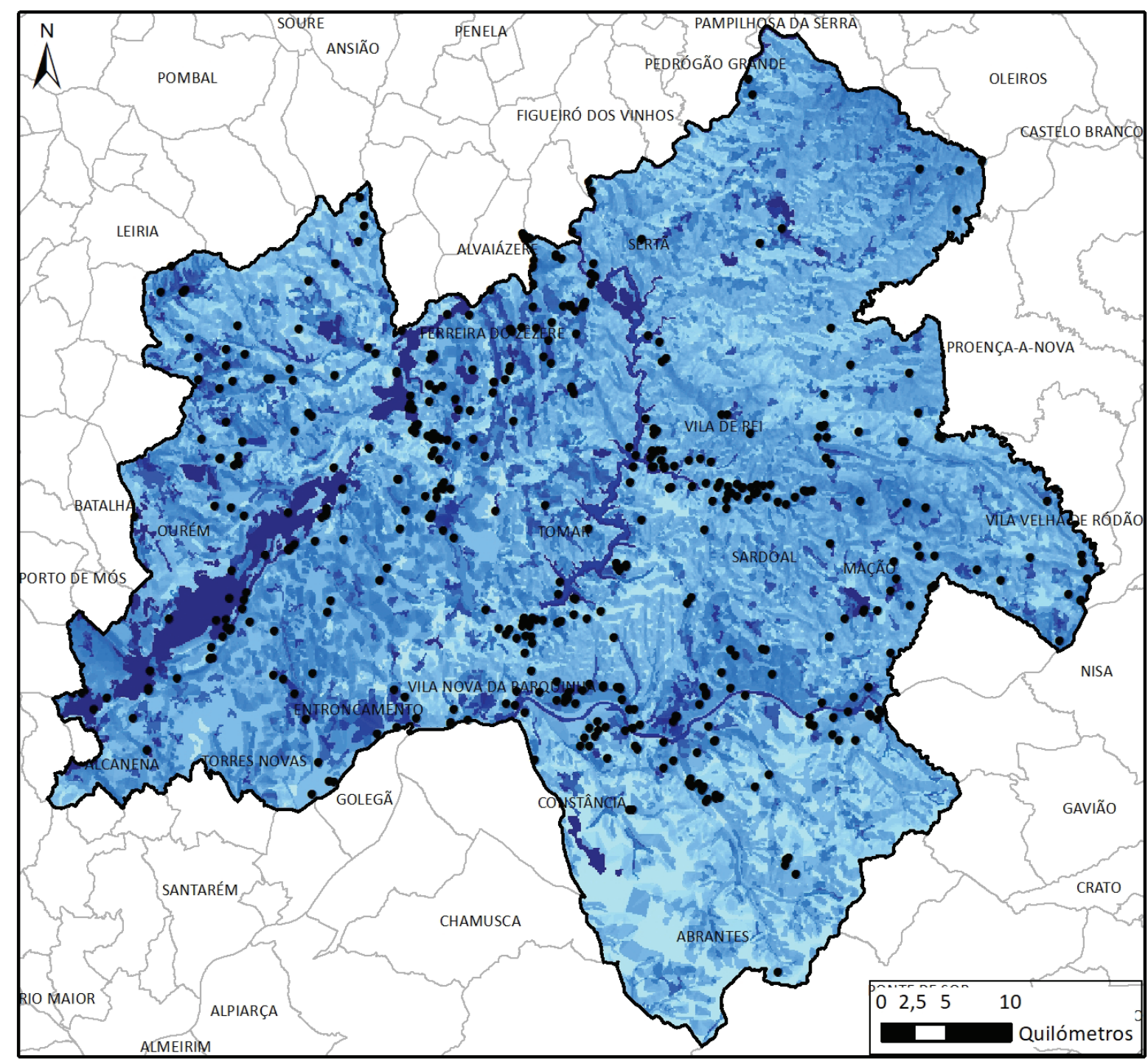

- Sitios Arqueológicos

Potencial (Método de Pesos)

Limite da Região Médio Tejo

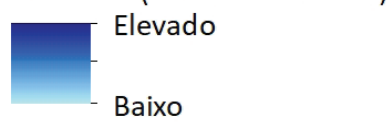

Fonte dos dados: CAOP2018

Sistema de Coordenadas: ETRS_1989_TM06_PT

Figura 10 - Áreas potenciais de existência de sítios arqueológicos, utilizando o método da sobreposição binária. 


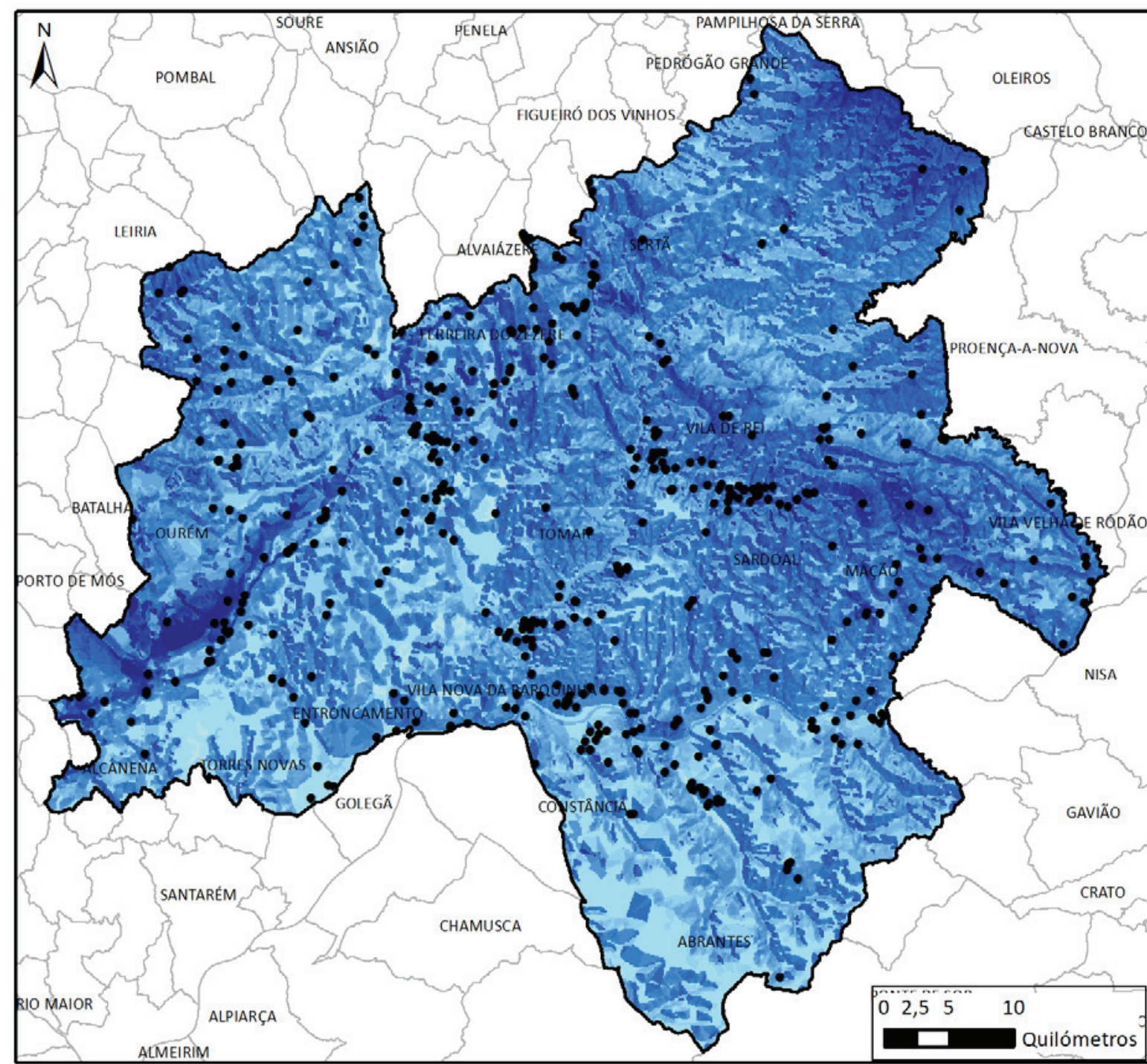

- Sitios Arqueológicos
$\square$ Limite da Região Médio Tejo

Potencial (Método da sobreposição binária)

Elevado

Baixo
Fonte dos dados: CAOP2018

Sistema de Coordenadas: ETRS_1989_TM06_PT

Figura 11 - Potencialidade de existência de sítios arqueológicos, utilizando o método de pesos. 


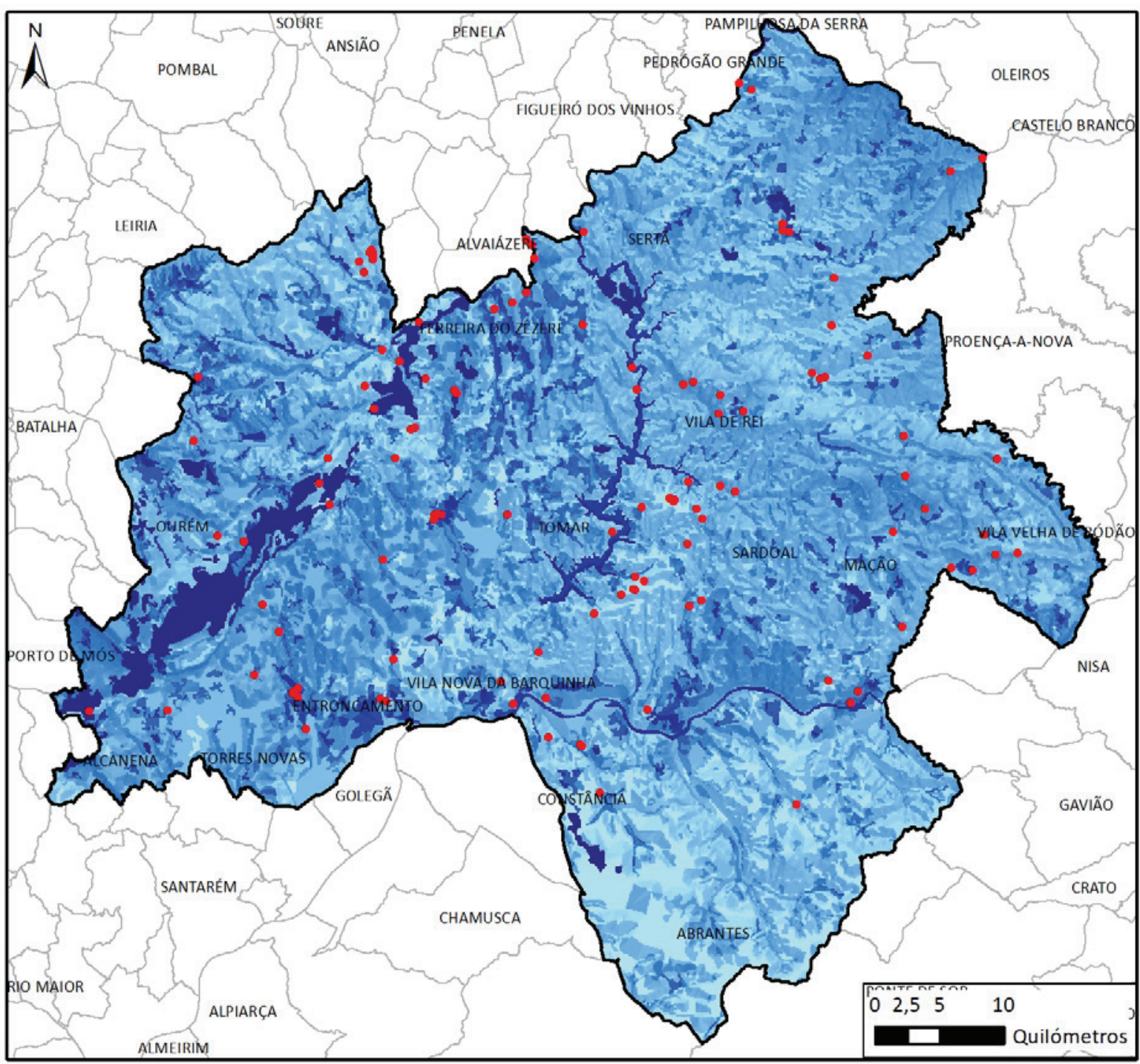

- Sitios Teste

Potencial (Método de Pesos) Elevado

Fonte dos dados: CAOP2018

Baixo

Figura 12 - Sítios de teste sobre modelo obtido através do método dos pesos. 


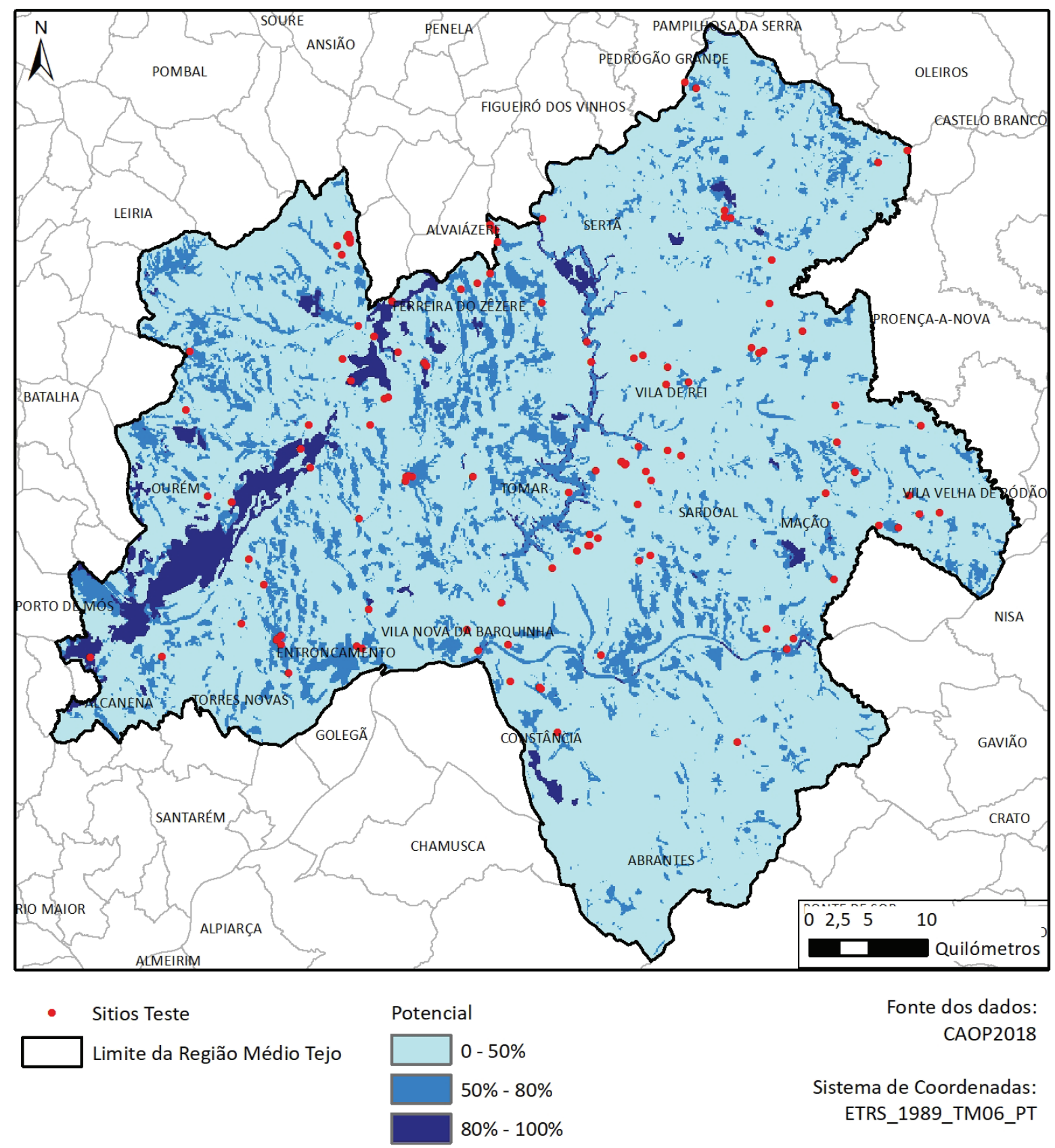

Figura 13 - Sítios de teste sobre classes de potencial modelo obtido através do método dos pesos. 


\begin{tabular}{|c|c|}
\hline Classe & Categoria CLC20o6 \\
\hline \multirow{6}{*}{ Social } & Aeroportos e aeródromos \\
\hline & Equipamentos desportivos, culturais e de lazer e zonas históricas \\
\hline & Indústria, comércio e equipamentos gerais \\
\hline & Redes viárias e ferroviárias e espaços associados \\
\hline & Tecido urbano contínuo \\
\hline & Tecido urbano descontínuo \\
\hline \multirow{7}{*}{ Agricultura } & Agricultura com espaços naturais e seminaturais \\
\hline & Culturas temporárias de sequeiro \\
\hline & Culturas temporárias de regadio \\
\hline & Culturas temporárias e/ou pastagens associadas a culturas permanentes \\
\hline & Olivais \\
\hline & Pomares \\
\hline & Vinhas \\
\hline \multirow{5}{*}{ Floresta } & Florestas de folhosas \\
\hline & Florestas de resinosas \\
\hline & Florestas mistas \\
\hline & Florestas abertas, cortes e novas plantações \\
\hline & Sistemas agroflorestais \\
\hline Sistemas Culturais complexos & Sistemas culturais e parcelares complexos \\
\hline Matos & Vegetação esclerofila \\
\hline \multirow{2}{*}{ Cursos de Água } & Cursos de água \\
\hline & Planos de água \\
\hline \multirow{2}{*}{ Extração de Inertes } & Áreas de extração de inertes \\
\hline & Áreas de deposição de resíduos \\
\hline
\end{tabular}

Tabela 1 - Classificação das classes de ocupação do solo.

\begin{tabular}{|c|c|}
\hline Variável Independente & Dmáx \\
\hline Declives & 0,148 \\
\hline Orientação de encostas & 0,141 \\
\hline Distância a rios & 0,200 \\
\hline Ocupação do solo & 0,084 \\
\hline
\end{tabular}

Tabela 2 - Valores de $\mathrm{D}_{\text {máx }}$ para cada variável independente. 


\begin{tabular}{|c|c|c|}
\hline Variáveis Independentes & Área $\left(\mathrm{m}^{2}\right)$ & Pesos \\
\hline Declives & 885034 & 0,111 \\
\hline Orientação de encostas & 885034 & 0,111 \\
\hline Distância a rios & 5346064 & 0,671 \\
\hline Ocupação do solo & 846056 & 0,106 \\
\hline Total & 7962188 & \\
\hline
\end{tabular}

Tabela 3 - Pesos das variáveis independentes.

\begin{tabular}{|c|c|c|}
\hline Potencial (\%) & Sítios & Frequência \\
\hline $0-50$ & 90 & $73,17 \%$ \\
\hline $50-80$ & 27 & $21,95 \%$ \\
\hline $80-100$ & 6 & $4,88 \%$ \\
\hline Total & 123 & $100,00 \%$ \\
\hline
\end{tabular}

Tabela 4 - Resultado do teste ao modelo obtido através do método de pesos. 



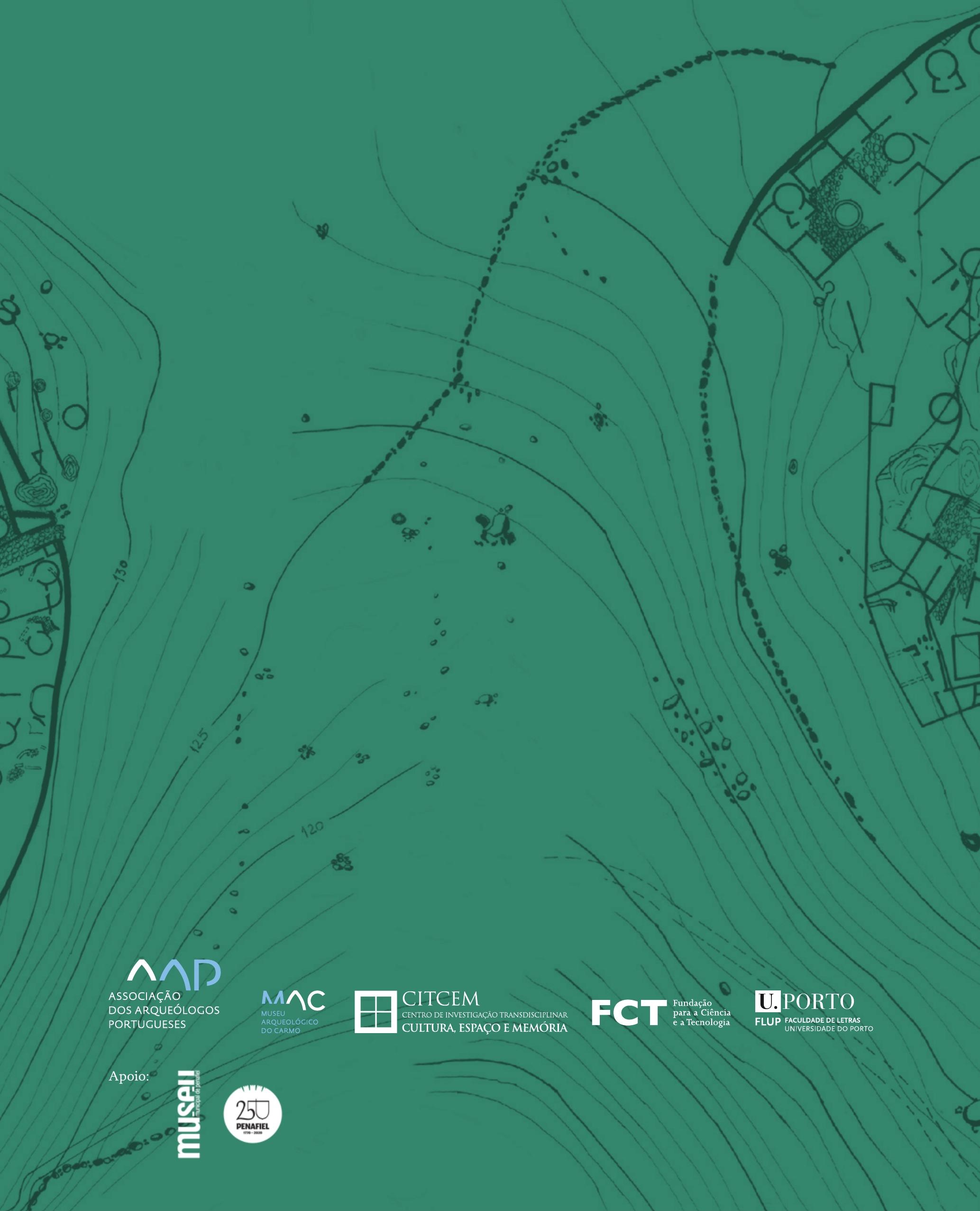

